\title{
Hemin and Cobalt Protoporphyrin Inhibit NLRP3 Inflammasome Activation by Enhancing Autophagy: A Novel Mechanism of Inflammasome Regulation
}

\author{
Katariina Nurmi $^{\mathrm{a}} \quad$ Ilona Kareinen $^{\mathrm{a}} \quad$ Juhani Virkanen $^{\mathrm{b}} \quad$ Kristiina Rajamäki $^{\mathrm{a}}$ \\ Vesa-Petteri Kouri ${ }^{c}$ Kirsi Vaali ${ }^{d}$ Anna-Liisa Levonen ${ }^{e}$ Nanna Fyhrquist ${ }^{f}$ \\ Sampsa Matikainen ${ }^{f}$ Petri T. Kovanen ${ }^{a}$ Kari K. Eklund ${ }^{9}$ \\ aWihuri Research Institute, ${ }^{b}$ Department of Geosciences and Geography, ${ }^{c}$ Clinicum, Faculty of Medicine, and \\ dMedicum, Department of Bacteriology and Immunology, University of Helsinki, Helsinki, eUnit of Biotechnology \\ and Molecular Medicine, A.I. Virtanen Institute for Molecular Sciences, University of Eastern Finland, Kuopio, ${ }^{f}$ Finnish \\ Institute of Occupational Health, and ${ }^{9}$ Department of Rheumatology, University of Helsinki and Helsinki University \\ Hospital, Helsinki, Finland
}

\section{Key Words}

Inflammasome · Autophagy · Macrophage $\cdot$ Hemin $\cdot$ Cobalt protoporphyrin · Heme oxygenase-1

\begin{abstract}
Inflammasomes are intracellular protein platforms, which, upon activation, produce the highly proinflammatory cytokines interleukin (IL)-1 $\beta$ and IL-18. Heme, hemin and their degradation products possess significant immunomodulatory functions. Here, we studied whether hemin regulates inflammasome function in macrophages. Both hemin and its derivative, cobalt protoporphyrin (CoPP), significantly reduced IL-1 $\beta$ secretion by cultured human primary macrophages, the human monocytic leukemia cell line and also mouse bone marrow-derived and peritoneal macrophages. Intraperitoneal administration of CoPP to mice prior to urate crystal-induced peritonitis alleviated IL-1 $\beta$ secretion to the peritoneal cavity. In cultured macrophages, hemin and CoPP inhibited NLRP3 inflammasome assembly by reducing the
\end{abstract}

\section{KARGER}

(c) 2016 S. Karger AG, Basel

E-Mail karger@karger.com

www.karger.com/jin amount of intracellular apoptosis-associated speck-like protein containing a caspase-recruitment domain (ASC). The reduction of ASC was associated with enhanced autophagosome formation and autophagic flux. Inhibition of autophagy prevented the CoPP-induced depletion of ASC, implying that the depletion was caused by increased autophagy. Our data indicate that hemin functions as an endogenous negative regulator of the NLRP3 inflammasome. The inhibition is mediated via enhanced autophagy that results in increased degradation of ASC. This regulatory mechanism may provide a novel approach for the treatment of inflammasomerelated diseases.

(c) 2016 S. Karger AG, Basel

\section{Introduction}

Macrophages are important effector cells of the innate immune system, acting in the first line of defense by sensing pathogens, cellular stress and tissue damage. Being 
responsible for the degradation of damaged or senescent erythrocytes, they are central cells for heme and hemin catabolism and iron homeostasis [1]. In response to danger signals, they secrete a myriad of proinflammatory cytokines. Of these, interleukin (IL)-1 $\beta$ and IL-18 are synthesized as precursor proteins, which need to be processed to their mature secreted forms by cytosolic multiprotein complexes, called inflammasomes [2]. Inflammasomes are activated by a variety of endogenous and exogenous activators, such as adenosine triphosphate (ATP) released from damaged cells, cholesterol and urate crystals as well as bacterial toxins [3-5]. The most studied inflammasome is the NLRP3 (nucleotide-binding domain and leucine-rich repeat containing family, pyrin domain containing 3 ). The NLRP3 inflammasome comprises the pattern recognition receptor NLRP3 and the adaptor protein ASC (apoptosis-associated speck-like protein containing a caspase-recruitment domain), which, upon activation, oligomerizes and recruits procaspase- 1 into the inflammasome complex [6]. The oligomerized ASC can be visualized as a large cytosolic 'ASC speck' [6]. Assembly of the inflammasome complex results in the autocleavage-mediated activation of caspase-1, thereby rendering it capable of cleaving pro-IL- $1 \beta$ and pro-IL- 18 into their mature secreted forms [2].

The activation of the NLRP3 inflammasome requires 2 separate signals. A priming signal, mediated by the activation of TLRs or cytokine receptors, induces the upregulation of the NLRP3 protein as well as the expression of pro-IL-1 $\beta$ [7]. The second signal is required for the induction of inflammasome assembly and the activation of the inflammasome complex. The exact mechanisms of such activation by the structurally and chemically diverse agonists of the NLRP3 inflammasome are currently not known, but the process has been suggested to involve potassium efflux, the production of reactive oxygen species (ROS), mitochondrial dysfunction and lysosomal destabilization that results in the release of cathepsin B [2].

Gain-of-function mutations of NLRP3, which result in excessive production of IL- $1 \beta$, underlie the pathogenesis of cryopyrin-associated autoinflammatory diseases, such as Muckle-Wells syndrome [3]. A role for enhanced NLRP3 inflammasome activity has also been implicated in the pathogenesis of some common disorders, such as gout, in which the urate crystals activate the NLRP3 inflammasome [8], and atherosclerosis [4,5]. Thus, it is obvious that stringent control mechanisms of inflammasome activation are needed. In contrast to the myriad of described activators of the NLRP3 inflammasome, much less is known about its negative regulation. Endogenous proteins, such as card- and pyrin-only proteins have been shown to inhibit the assembly of the NLRP3 inflammasome [9]. Several posttranslational modifications of inflammasome components also inhibit the assembly and activation of the NLRP3 inflammasome [10].

Macroautophagy, hereafter referred to as autophagy, is a vesicular trafficking process that targets damaged or superfluous cellular proteins and organelles for degradation [11]. Recently, autophagy was also shown to be capable of downmodulating the NLRP3 inflammasome activation and secretion of IL-1 $\beta$ [12-14]. Ubiquitinated inflammasome components are directed to autophagosomes by sequestosome 1 (SQSTM1) [13] and, subsequently, the fusion of autophagosomes with lysosomes results in the degradation of inflammasome components by lysosomal hydrolases [11]. Furthermore, damaged mitochondria, which are capable of promoting NLRP3 inflammasome activation, are constantly disposed of by autophagy [14]. However, the relationship between autophagy and the inflammasome-induced secretion of IL- $1 \beta$ is complex. For example, despite the role of autophagy as a negative regulator of inflammasome activation, it has also been shown to be required for the secretion of IL-1 $\beta$ [15].

In this study, we identified a novel negative regulatory mechanism of the activation of the NLRP3 inflammasome. We show that hemin and its derivative, cobalt protoporphyrin (CoPP), strongly inhibit the secretion of IL-1 $\beta$ by depleting the intracellular levels of ASC, thus abolishing the formation of ASC specks. Hemin and CoPP reduce the amount of ASC by increasing the autophagy, and thereby direct ASC for degradation in autophagosomes.

\section{Materials and Methods}

\section{Reagents}

Lipopolysaccharide (LPS) from the E. coli 0111:B4 strain (UltraPure LPS) from InvivoGen (San Diego, Calif., USA) was used for the priming of mouse macrophages and LPS from Sigma (Saint Louis, Mo., USA) was used for the priming of human primary macrophages and THP-1 macrophages. CoPP, hemin and bilirubin were from Sigma and tin mesoporphyrin (SnMP) was from Santa Cruz (Dallas, Tex., USA). CoPP (150 mM) and bilirubin $(5 \mathrm{mM})$ were dissolved in DMSO, while hemin $(5 \mathrm{mM})$ and SnMP (10 mM) were dissolved in $0.1 \mathrm{M} \mathrm{NaOH}$, neutralized and sterile filtered. Tricarbonyldichlororuthenium (II) dimer was from Sigma. The water-soluble carbon monoxide-releasing molecule tricarbonylchloro(glycinato)ruthenium(II) (CORM-3) was synthesized as previously described by Clark et al. [16], and stored at $-20^{\circ} \mathrm{C}$ as a lyophilisate. Nigericin sodium salt was from Sigma. Recombinant human apo-serum amyloid A (SAA) (isotype 1a), with an endotoxin level of $<1 \mathrm{EU} / \mu \mathrm{g}$ protein, as determined by the manufacturer, was from Peprotech (Princeton, N.J., USA). Mono-
66

J Innate Immun 2017;9:65-82 DOI: $10.1159 / 000448894$
Nurmi et al. 
Table 1. Mouse genotyping primers for RT-PCR

\begin{tabular}{lll}
\hline Primer & Sequence & Source \\
\hline HMOX1 F & $5^{\prime}$-AGG GGA AGA AGA CTC ATC GA-3' & B.S.R.C. Alexander Fleming, Greece \\
HMOX1 R & $5^{\prime}$-AGA AGG CTC GGA GGT TAA AT-3' & B.S.R.C. Alexander Fleming, Greece \\
LysM mutant & $5^{\prime}$-CCC AGA AAT GCC AGA TTA CG-3' & The Jackson Laboratory \\
LysM common & 5'-CTT GGG CTG CCA GAA TTT CTC-3' $^{\prime}$ & The Jackson Laboratory \\
LysM wt & $5^{\prime}$-TTA CAG TCG GCC AGG CTG AC-3' & The Jackson Laboratory \\
\hline
\end{tabular}

sodium urate (MSU) crystals were prepared from uric acid (Sigma) as previously described [17], and stored at $-20^{\circ} \mathrm{C}$. The endotoxin level of the crystals was found to be below the detection limit $(<0.03$ $\mathrm{EU} / \mathrm{ml}$ ) in the Pyrogent gel clot LAL assay (Lonza, Walkersville, Md., USA).

\section{Animals}

All animal experiments were conducted in conformity with Finnish regulations and the protocols were approved by The National Animal Experiment Board (permission No. ESAVI/ 4690/04.10.07/2015). All mice were housed with 5-6 mice per cage in conditions controlled for light/dark cycle, temperature and humidity. The mice had unlimited access to drinking water and food (standard chow: Teklad Global 16\% protein rodent diet, Harlan Laboratories, Madison, Wis., USA or Altromin 1314 FORTI, breeding diet rats/mice, Lage, Germany). Wild-type (WT) C57BL/6J mice, used for in vivo experiments, were obtained from Harlan Laboratories, Venray, The Netherlands. HMOX1 $1^{\mathrm{fl} /-}$ mice (on a mixed C57BL/6.129/Sv background) were obtained from Biomedical Sciences Research Center 'Alexander Fleming' (Vari, Greece) [18]. HMOX $1^{\mathrm{fl} /-}$ mice were further inbred to generate HMOX $1^{\mathrm{fl} / \mathrm{fl}}$ mice. Myeloid cell-specific ablation of Hmox 1 was generated as follows: HMOX1 $1^{\mathrm{fl} / \mathrm{fl}}$ mice were crossed with LysMCre $^{+/+}$mice (Jackson Laboratories, Bar Harbor, Maine, USA; $\mathrm{B} 6.129 \mathrm{P} 2-\mathrm{Lyz} 2^{\text {tm } 1(\mathrm{cre}) I f \circ} / \mathrm{J}$, the mouse strain is backcrossed to C57BL/ 6 for at least 6 generations) that express cre-deleter in the cells of myeloid cell lineage [19]. The LysMCre ${ }^{+/-} \mathrm{HMOX}^{\mathrm{fl} /-}$ mice obtained were backcrossed with $\mathrm{HMOX} 1^{\mathrm{fl} / \mathrm{fl}}$ mice to generate $\mathrm{LysMCre}^{+/-} \mathrm{HMOX}^{\mathrm{fl} / \mathrm{fl}}$ mice. Thioglycollate-elicited peritoneal macrophages (TEPMs) were collected from $\mathrm{LysMCre}^{+/-}$ $\mathrm{HMOX}^{\mathrm{fl} / \mathrm{fl}}$ and littermate controls LysMCre ${ }^{-/-} \mathrm{HMOX}^{\mathrm{fl} / \mathrm{fl}}$. Primer pairs used in genotyping are listed in table 1.

\section{Cell Cultures}

Human Primary Macrophages

Human mononuclear cells were isolated by density gradient centrifugation ( $800 \mathrm{~g}$ for $30 \mathrm{~min}$ ) in Ficoll-Paque PLUS (GE Healthcare Life Sciences, Uppsala, Sweden) from fresh buffy coats supplied by the Finnish Red Cross Blood Service (Helsinki, Finland). Buffy coats were obtained from healthy blood donors, after obtaining informed consent. The buffy coats were byproducts of the preparation of blood products for clinical use. The use of buffy coats in monocyte isolation was approved by the Finnish Red Cross Blood Service, Helsinki, Finland. Monocytes were allowed to adhere on cell culture wells, and nonadherent mononuclear cells were removed by washing with PBS w/o $\mathrm{Ca}^{2+}$ and $\mathrm{Mg}^{2+}$. The obtained monocytes were differentiated into macrophages using recombinant granulocyte macrophage colony-stimulating factor
(GM-CSF, 10 ng/ml; Nordic Biosite, Täby, Sweden) in macrophage serum-free medium (Gibco/Life Technologies, Carlsbad, Calif., USA), supplemented with $100 \mathrm{U} / \mathrm{ml}$ penicillin and $100 \mu \mathrm{g} /$ $\mathrm{ml}$ streptomycin, as previously described [20]. Each experiment with primary human macrophages was performed using macrophages derived from at least 4 donors.

Human Monocytic Leukemia Cell Line Macrophages

The human monocytic leukemia cell line (THP-1) was purchased from the American Type Culture Collection (ATCC, Catalog No. TIB-202, Manassas, Va., USA). Cells were maintained in RPMI 1640 supplemented with $2 \mathrm{mM} \mathrm{L-glutamine,} \mathrm{10 \%} \mathrm{fetal} \mathrm{bo-}$ vine serum, $25 \mathrm{mM}$ HEPES, $100 \mathrm{U} / \mathrm{ml}$ penicillin and $100 \mu \mathrm{g} / \mathrm{ml}$ streptomycin (all from Lonza). Monocyte-to-macrophage differentiation of THP-1 cells was induced by PMA (100 nM, 72 h) (Sigma). In the experiments, only PMA-differentiated THP-1 cells, i.e. THP-1 macrophages, were used.

\section{Mouse Macrophages}

Femoral and tibial bone marrow cells of WT mice were differentiated into bone marrow-derived macrophages (BMDMs) in the presence of $50 \mathrm{ng} / \mathrm{ml}$ of macrophage colony-stimulating factor (MCSF, Nordic Biosite) in RPMI 1640 supplemented with $2 \mathrm{mM} \mathrm{L}$ glutamine, 10\% fetal bovine serum, $25 \mathrm{mM}$ HEPES, $100 \mathrm{U} / \mathrm{ml}$ penicillin, $100 \mu \mathrm{g} / \mathrm{ml}$ streptomycin and $\beta$-mercaptoethanol (Sigma) for 7 days. For the collection of BMDMs, the mice were terminally anesthetized with isofluorane, and euthanasia was assured by cervical dislocation. Bone marrow was flushed with PBS, and erythrocytes were removed using red blood cell lysing buffer (Sigma). TEPMs were harvested from the peritoneal fluid 3 days after the injection of thioglycollate medium $(2 \mathrm{ml})$ into the peritoneal cavity. The cells were plated in cell culture wells and allowed to adhere in the presence or absence of LPS $(0.01 \mu \mathrm{g} / \mathrm{ml}, 3 \mathrm{~h})$ as a priming factor, after which they were washed and used for the experiments.

\section{MSU Peritonitis}

WT female C57BL/6J (aged 8-13 weeks) mice were used for in vivo experiments. Before the experiments, the mice received buprenorphine $(0.1 \mathrm{mg} / \mathrm{kg})$ subcutaneously for analgesia. Prior to the induction of peritonitis, they received intraperitoneal (i.p.) injection of CoPP ( $25 \mathrm{mg} / \mathrm{kg}$ in PBS, $300 \mu \mathrm{l} /$ mouse) or PBS $(300 \mu \mathrm{l} /$ mouse), followed by an i.p. injection of MSU crystals (3 mg in PBS, $300 \mu \mathrm{l} /$ mouse $)$ or PBS $(300 \mu \mathrm{l} /$ mouse $) 1 \mathrm{~h}$ later. Peritonitis was allowed to develop for $20 \mathrm{~h}$, after which the mice were terminally anesthetized by isoflurane, fully exsanguinated by cardiac puncture, and the peritoneal cavity was lavaged with $2 \mathrm{ml}$ of $0.1 \%$ BSA in PBS. The peritoneal fluid was centrifuged at $200 \mathrm{~g}$ for $5 \mathrm{~min}$ and the total cell counts were determined by using a Bürker chamber. 
Table 2. Primers and probes for quantitative real-time RT-PCR

\begin{tabular}{lll}
\hline Primer/probe & Sequence & Source \\
\hline Human & & our laboratory \\
GAPDH F & $5^{\prime}$-CCACATCGCTCAGACACCAT-3' & our laboratory \\
GAPDH R & $5^{\prime}$-GGCAACAATATCCACTTTACCAGAG-3' & our laboratory \\
GAPDH fluorogenic probe & $5^{\prime}$-FAM-CCAATACGACCAAATCCGTTGACTCC-BHQ1-3' & our laboratory \\
HMOX1 F & $5^{\prime}$-TCCTGCTCAACATCCAGCTC-3' & our laboratory \\
HMOX1 R & $5^{\prime}$-GGGCAGAATCTTGCACTTTG-3' & our laboratory \\
IL1B F & $5^{\prime}$-TTACAGTGGCAATGAGGATGAC-3' & our laboratory \\
IL1B R & $5^{\prime}$-GTCGGAGATTCGTAGCTGGAT-3' & our laboratory \\
IL1B fluorogenic probe & $5^{\prime}$-FAM-AACAGATGAAGTGCTCCTTCCAGGACC-BHQ1-3' & our laboratory \\
NLRP3 F & $5^{\prime}$-GGAGAGACCTTTATGAGAAAGCAA-3' & our laboratory \\
NLRP3 R & $5^{\prime}$-GCTGTCTTCCTGGCATATCACA-3' & our laboratory \\
NLRP3 fluorogenic probe & $5^{\prime}$-FAM-ACGTGCATTATCTGAACCCCACTTCGG-BHQ1-33' & {$[23]$} \\
\hline Mouse & & {$[23]$} \\
HMOX1 F & $5^{\prime}$-CCTCACTGGCAGGAAATCATC-3' & Applied \\
HMOX1 R & $5^{\prime}$-CCTCGTGGAGACGCTTTACATA-3' & Biosystems \\
\hline
\end{tabular}

\section{Inflammasome Activation in Cultured Macrophages}

Briefly, to activate the NLRP3 inflammasome, macrophages were first primed with the TLR 4 agonist LPS for $3 \mathrm{~h}$. Different final concentrations of LPS were used: human primary macrophages and THP-1 macrophages $(1 \mu \mathrm{g} / \mathrm{ml})$, and mouse macrophages $(0.01$ $\mu \mathrm{g} / \mathrm{ml})$. After priming, the cells were washed twice and incubated in the presence of the indicated concentrations of CoPP, hemin, CORM-3 or bilirubin (incubation times are given below). CoPP, hemin, CORM-3 and bilirubin were present during inflammasome activation.

Activation of the NLRP3 Inflammasome

After LPS-primed macrophages were incubated for $3 \mathrm{~h}$ in the presence of the indicated concentrations of CoPP or hemin, ATP $(5 \mathrm{mM}, 30 \mathrm{~min})$ or nigericin $(4 \mu \mathrm{M}, 1 \mathrm{~h})$ was added. To examine the effect of carbon monoxide, the LPS-primed human primary macrophages or THP-1 macrophages were incubated for $1 \mathrm{~h}$ in the presence of the indicated concentrations of CORM-3, after which ATP was added ( $5 \mathrm{mM}, 30 \mathrm{~min})$. The LPS-primed THP-1 macrophages were incubated in the presence of the indicated concentrations of bilirubin ( $20 \mathrm{~min}$ ) and activated with ATP ( $5 \mathrm{mM}, 30 \mathrm{~min})$. SAA was used for both the priming and activation of the NLRP3 inflammasome [21]. Macrophages were incubated in the presence of CoPP or hemin for $1 \mathrm{~h}$ prior to the addition of SAA (THP-1 macrophage activation: $3 \mu \mathrm{g} / \mathrm{ml}, 5 \mathrm{~h}$; BMDM activation: $2 \mu \mathrm{g} / \mathrm{ml}, 18 \mathrm{~h}$; human primary macrophage activation: $3 \mu \mathrm{g} / \mathrm{ml}, 18 \mathrm{~h}$ ). LPS-primed BMDMs were incubated in the presence of CoPP or hemin for $1 \mathrm{~h}$ prior to the addition of MSU crystals $(250 \mu \mathrm{g} / \mathrm{ml}, 18 \mathrm{~h})$. The enzymatic inhibitor of heme oxygenase-1 (HO-1), SnMP (5 $\mu \mathrm{M})$, was administered to THP- 1 macrophages $3 \mathrm{~h}$ prior to CoPP, and an inhibitor of autophagy, 3-methyl adenine (3-MA, 5 mM; Calbiochem, San Diego, Calif., USA), was added to the THP- 1 macrophages $23 \mathrm{~h}$ prior to CoPP.

\section{Measurement of Cell Death}

Trypan blue stain $(0.2 \% \mathrm{w} / \mathrm{v}, 2 \mathrm{~min})$ was routinely used to evaluate cell death. Cytotoxicity detection kit (Roche, Mannheim, Germany) based on the determination of lactate dehydrogenase $(\mathrm{LDH})$ release was used according to the manufacturer's protocol.

\section{ELISA Assays}

IL- $1 \beta$ and IL- 18 concentrations in cell culture medium and IL$1 \beta$ concentration from mouse peritoneal lavage were determined by using commercial sandwich ELISA assays (IL- $1 \beta$ assay by R\&D Systems, Minneapolis, Minn., USA; IL-18 assay by Medical and Biological Laboratories, Nagoya Aichi, Japan) according to the manufacturer's instructions.

\section{Quantitative Real-Time RT-PCR}

The quantitative real-time RT- PCR protocol used has been described previously [22]. The gene-specific primers and probes are given in table 2 .

\section{Immunoblot Analysis}

Cell culture media were concentrated using Vivaspin 6 centrifugal concentrator with a $5-\mathrm{kDa}$ cut-off (Sartorius, Göttingen, Germany). Adherent cells were collected and lysed in buffer containing $250 \mathrm{~mm}$ sucrose and $1 \mathrm{mM}$ EDTA and supplemented with $1 \times$ protease inhibitor cocktail, pH 7.0 (Roche, Mannheim, Germany). Proteins of cell lysates or concentrated medium samples were resolved by SDS-PAGE, and transferred to a PVDF membrane (Millipore, Billerica, Mass., USA). PVDF membranes were incubated $\mathrm{o} / \mathrm{n}$ at $4^{\circ} \mathrm{C}$ with antibodies raised against human IL-1 $\beta$ (proform detection: Santa Cruz Biotechnology; mature form detection: Cell Signaling, Danvers, Mass., USA), caspase-1 (AdipoGen, San Diego, Calif., USA), HO-1 (Santa Cruz Biotechnology), SQSTM1 (Santa Cruz Biotechnology), light chain 3 (LC3; Novus Biologicals, Littleton, Colo., USA), ASC (MBL international, Wo-
68 
burn, Mass., USA) and $\beta$-actin (Abcam, Cambridge, UK). HRPconjugated polyclonal goat-anti-mouse and rabbit-anti-goat antibodies (Dako, Glostrup, Denmark) were used as secondary antibodies. The band intensities were quantified by Bio-Rad ChemiDoc MP imaging system (USA). The band intensities were normalized to the intensity of $\beta$-actin bands, except for the intensity of LC3-II bands, which were compared to the intensity of LC3-I bands by calculating the LC3-II/LC3-I ratio.

\section{Cathepsin B/L activity measurement}

Nigericin- and SAA-induced release of cathepsin B from lysosomes [21, 24] was assessed as previously described [22]. Briefly, LPS-primed THP-1 macrophages were incubated in the presence of $2.5 \mu \mathrm{M}$ CoPP for $3 \mathrm{~h}$, after which nigericin was added $(4 \mu \mathrm{M}, 1 \mathrm{~h})$. When SAA was used as the activator, THP-1 macrophages were incubated in the presence of $\mathrm{CoPP}(2.5 \mu \mathrm{M}, 1 \mathrm{~h})$ and then activated with SAA $(3 \mu \mathrm{g} / \mathrm{ml}, 5 \mathrm{~h})$. Cathepsin B/L-dependent hydrolysis of the fluorogenic substrate Z-Phe-Arg-AMC (Enzo Life Sciences, Farmingdale, N.Y., USA) $(40 \mu \mathrm{M})$ in the medium was measured (excitation at $355 \mathrm{~nm}$, emission at $486 \mathrm{~nm}$ ) after $1 \mathrm{~h}$ of incubation at $37^{\circ} \mathrm{C}$.

\section{Immunofluorescence Microscopy}

ASC speck detection was performed as previously described [22]. Briefly, THP-1 macrophages were incubated in the presence of CoPP $(2.5 \mu \mathrm{M})$ or hemin $(5 \mu \mathrm{M})$ for $3 \mathrm{~h}$ before the addition of the NLRP3 inflammasome activator, nigericin $(4 \mu \mathrm{M}, 1 \mathrm{~h})$. PFAfixed cells were stained with anti-ASC antibody (MBL International), goat-anti-mouse IgG1 Alexa Fluor 488 (Invitrogen, Eugene, Oreg., USA) was used as secondary antibody and the nuclei were stained with DAPI. The speck formation was quantified by epifluorescence microscopy. The number of specks/field were divided by the number of cells/field, and expressed as percentages; 10 different fields (on average 200 cells/field) were counted in each of the 4 experiments.

For the SQSTM1/ASC double-immunofluorescence staining, THP-1 macrophages were incubated in the presence of CoPP $(5 \mu \mathrm{M})$ for 2 or $4 \mathrm{~h}$. PFA-fixed cells were stained with antibodies for ASC (Adipogen, San Diego, Calif., USA) and SQSTM1 (Santa Cruz Biotechnology). Goat-anti-rabbit IgG $(\mathrm{H}+\mathrm{L})$ Alexa Fluor 594 for ASC and goat-anti-mouse IgG1 Alexa Fluor 488 for SQSTM1 (both from Invitrogen) were used as secondary antibodies. The nuclei were stained with DAPI.

\section{Measurement by Inductively Coupled Plasma Mass Spectrometry}

THP-1 macrophages were incubated in the presence of CoPP $(2.5 \mu \mathrm{M}, 3 \mathrm{~h})$, after which the NLRP3 inflammasome was activated with nigericin $(4 \mu \mathrm{M}, 1 \mathrm{~h})$. Analysis of intracellular potassium con-

Fig. 1. CoPP and hemin inhibit the secretion of IL-1 $\beta$ by human and mouse macrophages. Unprimed or LPS-primed mouse BMDMs were incubated for $3 \mathrm{~h}(\mathbf{a}, \mathbf{c})$ or $1 \mathrm{~h}(\mathbf{b}, \mathbf{d})$ in the presence of CoPP or hemin. The NLRP3 inflammasome was then activated with ATP (a), SAA (b), nigericin (Nig; c) and MSU crystals (d), and the secretion of mature IL- $1 \beta$ was measured by ELISA. Unprimed or LPS-primed human primary macrophages were incubated for $3 \mathrm{~h} \mathrm{(e)} \mathrm{or} 1 \mathrm{~h}(\mathbf{f})$ in the presence of CoPP or hemin. Thereafter, the stimulation of the NLRP3 inflammasome was in- centration was performed by inductively coupled plasma mass spectrometry (ICP-MS) as previously described [22]. Briefly, THP-1 macrophages from 6 parallel wells were lysed in 70\% nitric acid (Romil-SpA, Cambridge, UK), and the potassium concentration was determined according to ISO 17294-2 [25] in helium mode (Agilent 7500 ce/cx ICP-MS, Alpharetta, Ga., USA). Analyses were performed at the Department of Geosciences and Geography, University of Helsinki. Elemental recovery of $101 \%$ was measured using the National Institute of Standards and Technology standard as the reference (NIST-1577C, Gaithersburg, Md., USA).

\section{ROS Generation Assays}

To analyze cytosolic ROS formation, THP-1 macrophages were incubated in the presence of hemin $(5 \mu \mathrm{M})$ or $\operatorname{CoPP}(5 \mu \mathrm{M})$ for 1 or $3 \mathrm{~h}$, after which the cells were stimulated with nigericin or left nonstimulated $(4 \mu \mathrm{M}, 1 \mathrm{~h})$. Before the measurement, the cells were washed and incubated for $30 \mathrm{~min}$ at $37^{\circ} \mathrm{C}$ in $5 \% \mathrm{CO}_{2}$ in PBS with $\mathrm{Ca}^{2+}$ and $\mathrm{Mg}^{2+}$ containing $50 \mu \mathrm{M}$ dihydrorhodamine 123 (DHR 123) (Sigma), hemin or CoPP, and nigericin. The cells were lysed in $200 \mu \mathrm{l}$ of $1 \%$ TritonX and the fluorescence was measured immediately with a plate reader (Hidex Plate Chameleon 5, Turku, Finland), with excitation at $500 \mathrm{~nm}$ and emission at $536 \mathrm{~nm}$.

To assess the accumulation of mitochondrial ROS, THP-1 macrophages were incubated in the presence of hemin $(5 \mu \mathrm{M})$ or $\operatorname{CoPP}(5 \mu \mathrm{M})$ for 1 or $2 \mathrm{~h}$, and then stimulated with nigericin or left unstimulated $(4 \mu \mathrm{M}, 1 \mathrm{~h})$. Before detachment, the cells were washed and incubated for $30 \mathrm{~min}$ at $37^{\circ} \mathrm{C}$ in $5 \% \mathrm{CO}_{2}$ in $\mathrm{PBS}$ with $\mathrm{Ca}^{2+}$ and $\mathrm{Mg}^{2+}$ containing $5 \mu \mathrm{M}$ mitoSOX (Molecular Probes, Eugene, Oreg., USA), hemin or CoPP, and nigericin. The cells were washed, incubated with trypsin $(0.25 \%)$ for $5 \mathrm{~min}$ at $37^{\circ} \mathrm{C}$ and detached by gentle pipetting, which required an average of $1 \mathrm{~h}$. At the time point of the measurement, the cells had been incubated in the presence of CoPP and hemin for 2 or $4 \mathrm{~h}$. The detached cells were resuspended in cold PBS w/o Ca ${ }^{2+}$ and $\mathrm{Mg}^{2+}$ containing $1 \% \mathrm{FBS}$ and the mitochondrial ROS were measured by flow cytometry (BD Accuri, San José, Calif., USA; 10000 events counted in each measurement) and the results were analyzed by FlowJo v10.

\section{Statistical Analysis}

Statistical analyses were performed using GraphPad Prism v6 for Windows. Statistical differences between groups were identified using one-way analysis of variance (ANOVA) followed by the Tukey, Dunnett or Holm-Sidak multiple comparisons tests when appropriate. Nonnormally distributed data was $\log _{2}$-transformed before statistical testing, and is indicated in the figure legends. Data are presented as means \pm standard deviation (SD) of data from $\geq 3$ independent experiments.

duced by ATP (e) or SAA (f). g THP-1 macrophages were incubated for $3 \mathrm{~h}$ in the presence of CoPP or hemin, and thereafter activated with nigericin. Secretion of mature IL-1 $\beta$ was measured by ELISA, and is expressed as fold changes compared to the activated cells. Data represent the means \pm SD of $3(\mathbf{c}), 4(\mathbf{a}, \mathbf{b}, \mathbf{d}, \mathbf{f}, \mathbf{g})$ and 6 (e) individual experiments. a-g Statistical significance was evaluated with $\log _{2}$-transformed values. ${ }^{*} \mathrm{p} \leq 0.05 ;{ }^{* *} \mathrm{p} \leq 0.01$; $* * * \mathrm{p} \leq 0.001 ;{ }^{* * * *} \mathrm{p} \leq 0.0001$.

(For figure see next page.)
Hemin and CoPP Inhibit NLRP3

Activation by Enhancing Autophagy
J Innate Immun 2017;9:65-82

DOI: $10.1159 / 000448894$ 


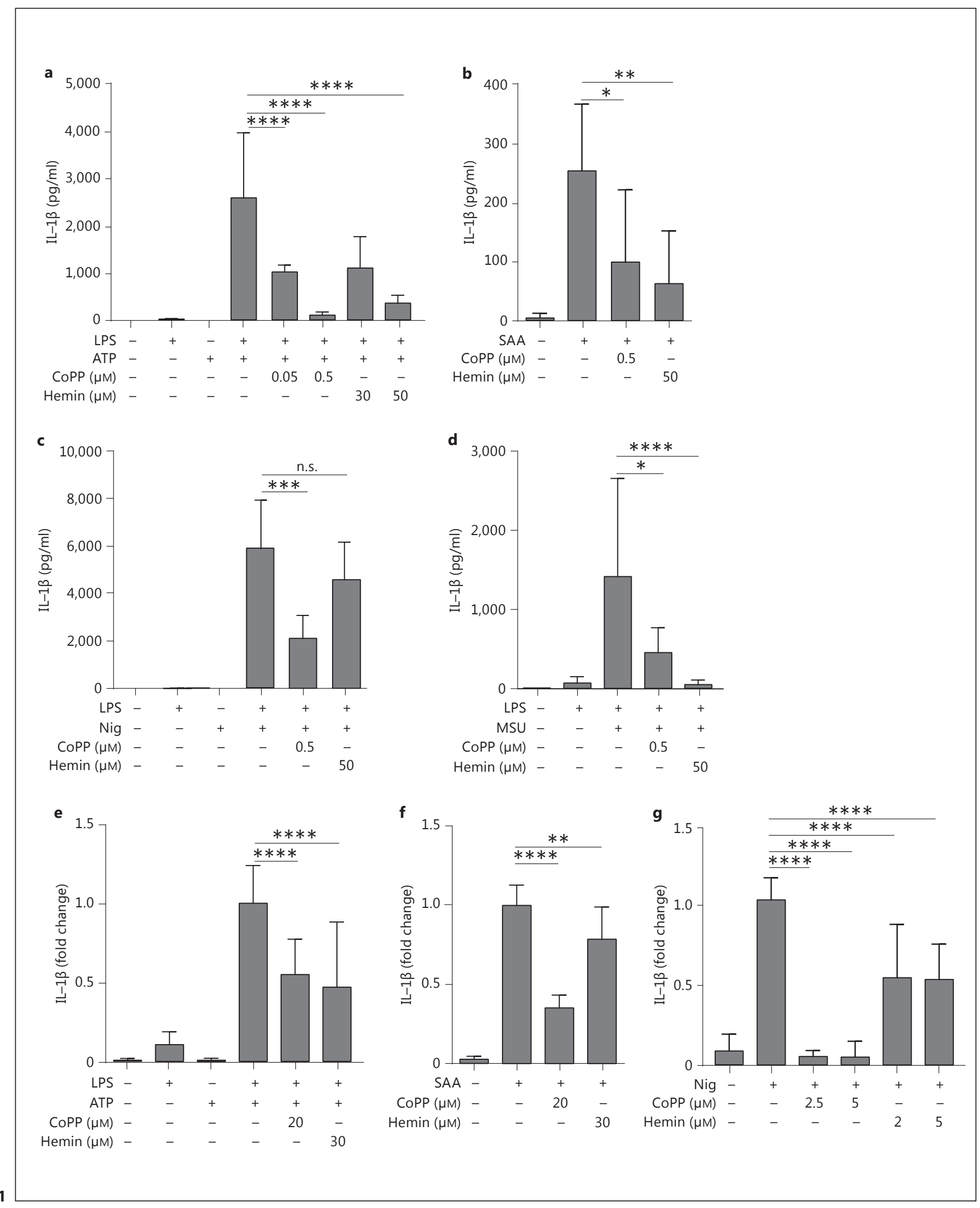




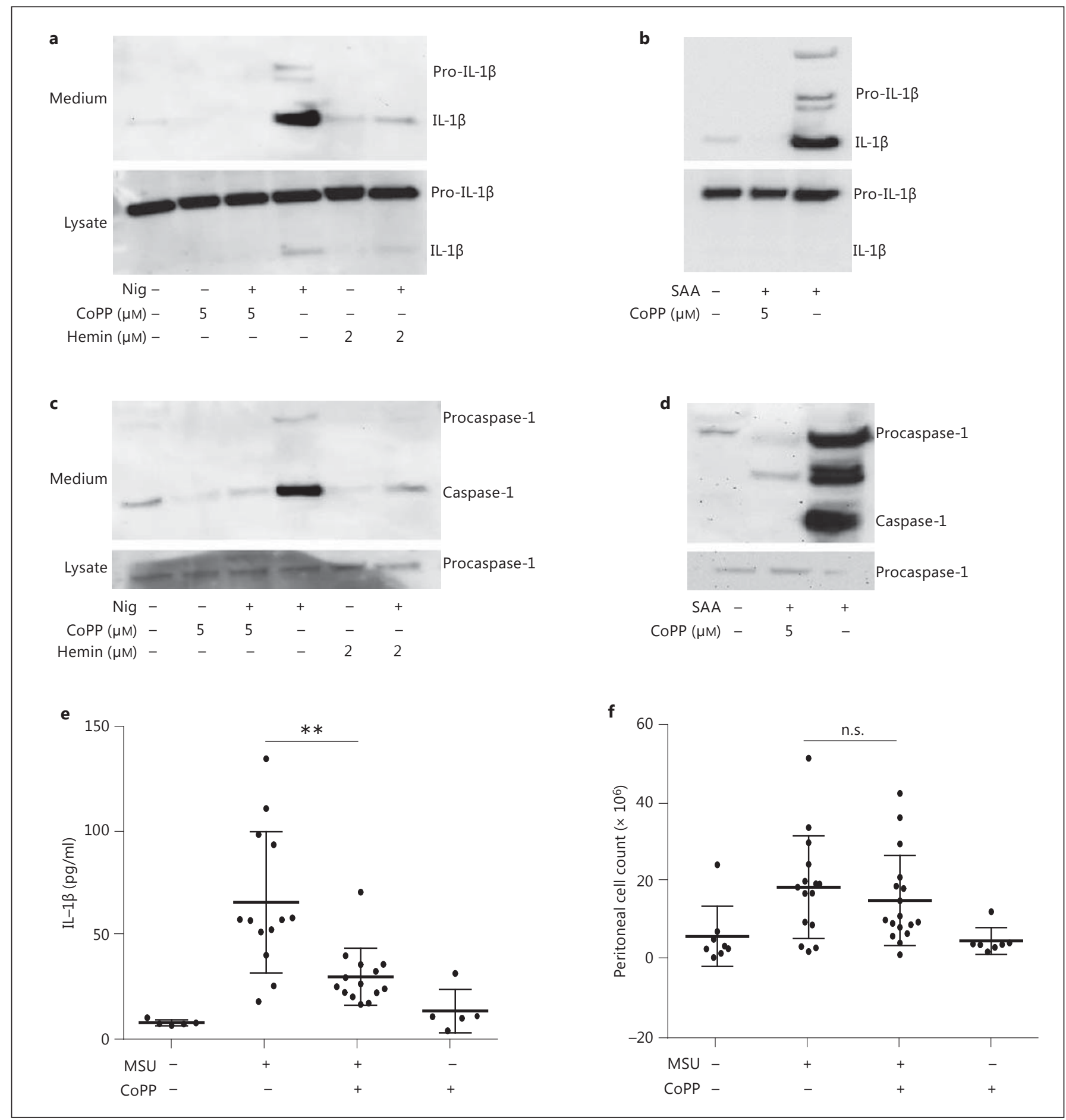

Fig. 2. CoPP and hemin inhibit inflammasome activation. Cleavage of pro-IL- $1 \beta(35 \mathrm{kDa})$ to mature IL- $1 \beta(17 \mathrm{kDa})$ and of procaspase-1 $(45 \mathrm{kDa})$ to active caspase- $1(20 \mathrm{kDa})$ were assessed from Western blots of the cell culture media. THP-1 macrophages were incubated for $3 \mathrm{~h}$ in the presence of CoPP or hemin $(\mathbf{a}, \mathbf{c})$ or for $1 \mathrm{~h}$ in the presence of CoPP (b, d), after which, nigericin (Nig; $\mathbf{a}$, c) or SAA (b, d) was added. The Western blots presented are representative of at least 4 individual experiments. e, f Mice were injected i.p. with CoPP (25 mg/kg) or vehicle (PBS) $1 \mathrm{~h}$ before challenge with MSU crystals. Peritonitis was allowed to develop for $20 \mathrm{~h}$, after which, the peritoneal cavities of the mice were lavaged. e IL- $1 \beta$ concentration was measured by ELISA and cell numbers (f) were counted from the peritoneal lavage fluid. ${ }^{* *} \mathrm{p} \leq 0.01$. Each data point in $\mathbf{e}$ and $\mathbf{f}$ represents 1 mouse; statistical significance was evaluated with $\log _{2}$-transformed values. Data represent the means $\pm \mathrm{SD}$. 


\section{Results}

\section{Hemin and CoPP Reduce the Secretion of IL-1 $\beta$ by} Mouse and Human Macrophages

Mouse BMDMs, human primary macrophages or THP-1 macrophages were incubated in the presence of hemin or CoPP, after which the NLRP3 inflammasome was activated with ATP, SAA, MSU crystals or nigericin. As demonstrated in figure 1 , the secretion of IL- $1 \beta$, induced by different NLRP3 inflammasome activators, was significantly reduced in the presence of hemin or CoPP, in both mouse (fig. 1a-d) and human (fig. 1e, f) macrophages. A similar inhibitory effect was also observed in the THP-1 macrophages (fig. 1g). It should be noted that THP-1 macrophages were more sensitive to the inhibitory effect of CoPP and hemin and mouse BMDMs to the effect of CoPP when compared to human primary macrophages.

The IL- $1 \beta$ ELISA results were confirmed by Western blot studies, which showed reduced secretion of the mature form $(17 \mathrm{kDa})$ of IL-1 $\beta$ (fig. $2 \mathrm{a}$, b; online suppl. fig. 1A-C; for all online suppl. material, see www. karger.com/doi/10.1159/000448894) and processed active form $(20 \mathrm{kDa})$ of caspase-1 (fig. $2 \mathrm{c}$, d; online suppl. fig. 1D-F) in the THP-1 macrophages in the presence of hemin or CoPP. The incubation of the cells in the presence of CoPP or hemin had no effect on cell viability (online suppl. fig. 1G, H). Inhibition of the NLRP3 inflammasome by CoPP was also evident in vivo (fig. 2e). Thus, i.p. injection of CoPP $1 \mathrm{~h}$ prior to induction of peritonitis by i.p. administration of MSU crystals significantly reduced the secretion of IL- $1 \beta$ into the peritoneal cavity. Pretreatment with CoPP also tended to diminish leukocyte influx into the peritoneal cavity, but the reduction was not statistically significant (fig. 2f).

\section{Hemin and CoPP Do Not Interfere with the Priming of the NLRP3 Inflammasome}

Before NLRP3 inflammasome can be activated, a separate priming step is required during which the expression of NLRP 3 receptor and the proform of IL- $1 \beta$ are induced [7]. So next, we studied whether hemin and CoPP reduced IL- $1 \beta$ secretion by inhibiting the priming step. For this purpose, human primary macrophages were primed via the activation of TLR4 with LPS and were then treated with hemin or CoPP. Treatment with both compounds did not reduce the expression of IL1B or NLRP3 (fig. 3a, b). Likewise, no reduction was observed in the expression of $I L 1 B$ or NLRP3 in THP-1 macrophages (online suppl. fig. 1I, J). On the contrary, CoPP and hemin rather en- hanced the expression of IL $1 B$ in human primary macrophages. The LPS-induced expression of NLRP3 is known to be transient $[5,7]$ and thus, at the time point of the measurement, the expression had already returned to baseline. These results are in agreement with the results obtained from Western blots of cell lysates from THP-1 macrophages, showing that neither CoPP nor hemin had any significant effect on the intracellular protein levels of procaspase-1 or pro-IL-1 $\beta$ (fig. $3 c$, d; online suppl. fig. 2A-F). However, a slight reduction in protein levels of intracellular NLRP3 was observed in the CoPP-treated THP-1 macrophages. Furthermore, hemin and CoPP also reduced the secretion of the mature IL-18 in the THP-1 macrophages (fig. 3e), the proform of which is constitutively expressed in these cells, and so priming is not required for its secretion [26]. The data above indicate that the inhibition of IL- $1 \beta$ secretion by hemin or CoPP is not caused by the inhibition of the priming step, but instead by that of NLRP3 inflammasome activation.

\section{CoPP Inhibits Release of Cathepsin B and Production}

of Mitochondrial ROS but Has No Effect on Potassium Efflux

The intracellular events upstream of NLRP3 inflammasome activation include potassium efflux, leakage of lysosomal protease cathepsin B and ROS formation. The effect of CoPP on the potassium efflux was assessed by measuring the concentration of cellular potassium using ICP-MS. Activation of the NLRP3 inflammasome in THP-1 macrophages with nigericin significantly decreased the intracellular potassium concentration in the treated cells (fig. 4a). However, preincubation of the cells in the presence of CoPP had no impact on the intracellular potassium concentration, in either the nigericin-activated or nonactivated THP-1 macrophages.

Release of cathepsin B from intact lysosomes during nigericin- or SAA-induced activation is closely associated with the activation of the NLRP3 inflammasome [21,24]. The release of lysosomal cathepsins into cell culture medium has been shown to accompany the secretion of mature IL-1 $\beta$ [15]. Both nigericin and SAA induced a robust release of enzymatically active cathepsin $B$ into the cell culture medium from the THP-1 macrophages, which was significantly inhibited by CoPP (fig. 4b, c). The mechanisms needed for the secretion of IL- $1 \beta$ are not explicitly known, but autophagy-driven secretion of IL- $1 \beta$, during which IL- $1 \beta$ is released from autophagosomal compartments, has been suggested [15]. It is therefore possible that the reduced release of active cathepsin B from CoPPtreated cells reflected the diminished secretion of IL- $1 \beta$ 


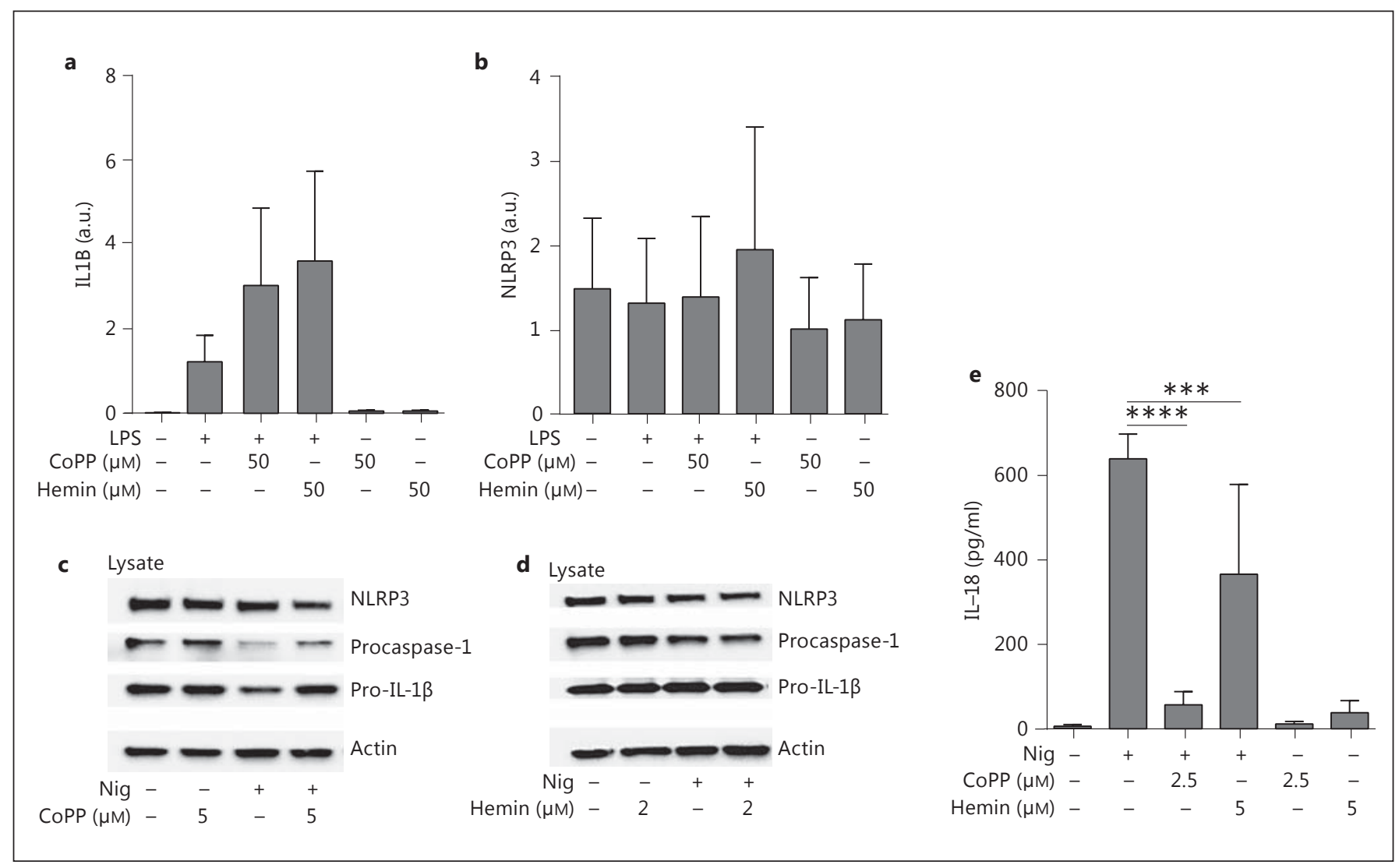

Fig. 3. Hemin and CoPP do not inhibit priming of NLRP3 inflammasome. a, b Unprimed or LPS-primed human primary macrophages were incubated for $3 \mathrm{~h}$ in the presence of CoPP and hemin. LPS-induced expression of IL1B (a) and NLRP3 (b) mRNA was determined by quantitative real-time RT-PCR. The gene expression is expressed as arbitrary units (a.u.). c, d THP-1 macrophages were incubated for $3 \mathrm{~h}$ in the presence of $\operatorname{CoPP}(\mathbf{c})$ and hemin $(\mathbf{d})$, and activated with nigericin (Nig.). The intracellular levels of
NLRP3 (108 kDa), procaspase-1 (45 kDa) and pro-IL- $\beta$ (37 kDa) were assessed from Western blots of the cell lysates. The Western blots shown are representatives of 4 individual experiments. e To assess the secretion of active IL-18, THP-1 macrophages were incubated for $3 \mathrm{~h}$ in the presence of CoPP or hemin, after which, the cells were activated with nigericin. ${ }^{* * *} \mathrm{p} \leq 0.001$; ${ }^{* * *} \mathrm{p} \leq 0.0001$. The secretion of IL-18 was measured by ELISA. Data represent the means \pm SD of $3(\mathbf{e})$ and $4(\mathbf{a}, \mathbf{b})$ individual experiments. and the inflammasome components from the autolysosomes rather than the impairment of cathepsin B-dependent NLRP3 inflammasome activation.

Mitochondrial ROS has been implicated in the activation of the NLRP3 inflammasome [14]. To assess the effect of hemin and CoPP on mitochondrial superoxide generation, a fluorogenic probe (mitoSOX), which specifically detects mitochondrial superoxide, was used. Hemin and CoPP alone had no effect on the generation of mitochondrial ROS compared to the nontreated cells, but inflammasome activation by nigericin induced a robust accumulation of mitochondrial ROS (fig. $4 \mathrm{~d}$, e). Importantly, the incubation of cells with hemin or CoPP prior to the inflammasome activation reduced the accumulation of mitochondrial ROS.

Hemin and CoPP Inhibit NLRP3

Activation by Enhancing Autophagy
Heme and hemin are pro-oxidant molecules that have been shown to induce ROS formation by nicotinamide adenine dinucleotide phosphate (NADPH) oxidase in macrophages [27]. To determine the effect of hemin and CoPP on cytosolic ROS formation, we assessed the fluorescence intensity of DHR 123 staining in nonstimulated and nigericin-stimulated THP-1 macrophages. DHR123 detects cytosolic ROS species generated via NADPH oxidase activation, among other sources. In both stimulated and nonstimulated THP-1 macrophages, the generation of ROS was increased by hemin and, to a lesser extent, with CoPP when compared to nontreated cells (fig. 4f). Taken together, the reduced accumulation of mitochondrial ROS by hemin and CoPP could have contributed to their inhibitory effect on nigericin-induced NLRP3 in- 


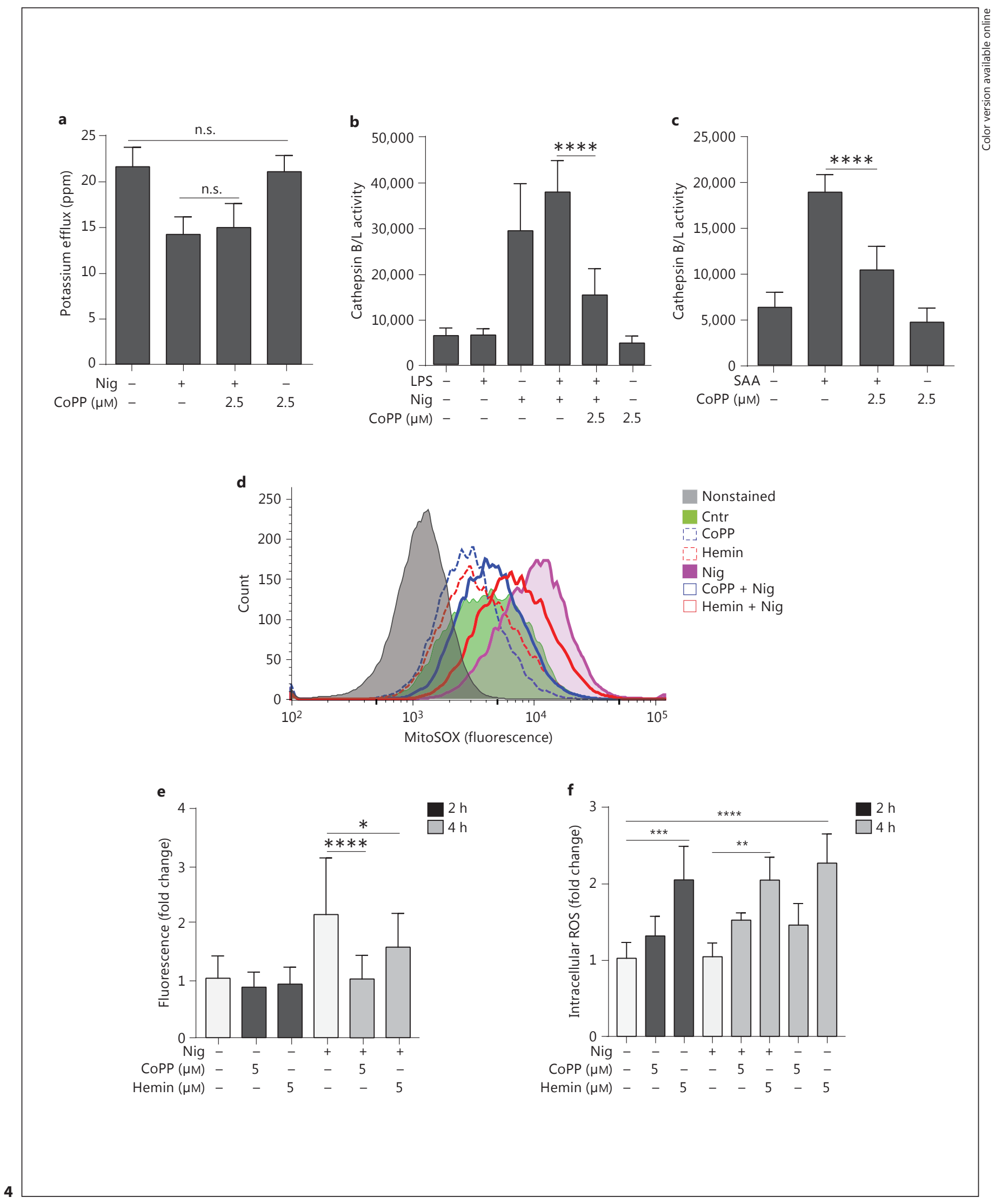

(For legend see next page.) 
flammasome activation whereas their effect on NADPH oxidase-generated ROS is a less probable mechanism for the inhibition.

\section{Inhibition of NLRP3 Inflammasome by Hemin and} CoPP Is Partially Dependent on Heme Oxygenase-1

Since heme/hemin and CoPP are well-established inducers of the heme-catabolizing antioxidant enzyme HO-1 [28], we next studied whether the inhibitory effect of hemin and CoPP on NLRP3 inflammasome activation could be mediated via the induction of HO-1. Hemin and $\mathrm{CoPP}$ induced $\mathrm{HO}-1$ protein expression during the first $4 \mathrm{~h}$ after their addition to the THP-1 macrophages (fig. 5a; online suppl. fig. 2G), and a more robust expression was observed later at the 8-hour and 16-hour time points. Stannous mesoporphyrin (SnMP), a competitive inhibitor of HO-1 enzymatic activity [28], strongly reversed the CoPP-induced inhibition of IL- $1 \beta$ secretion (fig. $5 b$ ). Furthermore, of the products of heme/hemin degradation, carbon monoxide, but not bilirubin, attenuated the secretion of IL- $1 \beta$ (fig. 5 c; online suppl. fig. $2 \mathrm{H}, \mathrm{I}$ ).

The role of HO- 1 as an endogenous inhibitor of the NLRP3 inflammasome was further studied in TEPMs obtained from mice carrying a myeloid cell line-targeted deletion of Hmox 1 (LysMCre $\left.{ }^{+/-} \mathrm{HMOX}^{\mathrm{fl} / \mathrm{fl}}\right)$. A trend of reduced Hmoxl expression was observed in the HO-1-de-
Fig. 4. Hemin and CoPP inhibit the release of cathepsin B and the generation of mitochondrial ROS. a THP-1 macrophages were incubated in the presence of CoPP for $3 \mathrm{~h}$ and activated with nigericin (Nig.). The potassium level of the cell lysates was determined by ICP-MS. b, c Unprimed or LPS-primed THP-1 macrophages were incubated in the presence of CoPP for $3 \mathrm{~h} \mathrm{(b)}$ or $1 \mathrm{~h} \mathrm{(c)} \mathrm{be-}$ fore the NLRP3 inflammasome was activated with nigericin (b) or SAA (c), and the release of active lysosomal proteases was detected by measuring the cleavage of cathepsin $\mathrm{B} / \mathrm{L}$ substrate (excitation at $355 \mathrm{~nm}$, emission at $486 \mathrm{~nm}$ ) in the cell culture medium. d-f THP-1 macrophages were incubated in the presence of CoPP or hemin for the indicated times and activated with nigericin. d, e The cells were stained with mitoSOX (30 min), detached and analyzed by flow cytometry. Control (Cntr) cells represent the nontreated cells stained with mitoSOX. d The flow cytometric analysis shown is representative of 4 individual experiments. e Fold changes of mean fluorescence of flow cytometric analyses. $\mathbf{f}$ THP-1 macrophages were stained with DHR 123, and the fluorescence from cell lysates was analyzed by plate reader (excitation at $500 \mathrm{~nm}$, emission at $536 \mathrm{~nm}$ ). Given time points indicate the time passed from the administration of CoPP or hemin at the time point of the measurement (see Materials and Methods). Data represent the means \pm SD of $3(\mathbf{a}), 4(\mathbf{e})$ or $6(\mathbf{b}, \mathbf{c}, \mathbf{f})$ individual experiments. ${ }^{*} \mathrm{p} \leq 0.05$; ** $\mathrm{p} \leq 0.01 ;{ }^{* * *} \mathrm{p} \leq 0.001$; $^{* * *} \mathrm{p} \leq 0.0001$.
Fig. 5. Inhibition of HO-1 enzymatic activity reverses the effect of CoPP. The expression of HO-1 protein induced by CoPP or hemin in THP-1 macrophages was determined at 4,8 and $16 \mathrm{~h}$. a THP- 1 macrophages were incubated in the presence of CoPP or hemin for the indicated times, and HO-1 $(32 \mathrm{kDa})$ was assessed from the cell lysates by Western blot (representative of 4 individual experiments). b The enzymatic activity of HO-1 was inhibited by stannous mesoporphyrin (SnMP) for $3 \mathrm{~h}$, prior to the treatment of THP-1 macrophages with CoPP (3 h), after which, the cells were activated with nigericin (Nig). ${ }^{* *} \mathrm{p} \leq 0.01$. c Unprimed or LPS-primed human primary macrophages were incubated for $1 \mathrm{~h}$ in the presence of CORM-3 or its inactivated form (iCORM-3), and thereafter activated with ATP. The secretion of IL- $1 \beta$ was measured by ELISA; statistical significance was evaluated with $\log _{2}$-transformed values. * $\mathrm{p} \leq 0.05$; ** $\mathrm{p} \leq 0.01$. Data represent the means \pm SD of $3(\mathbf{b})$ or 5 (c) individual experiments.

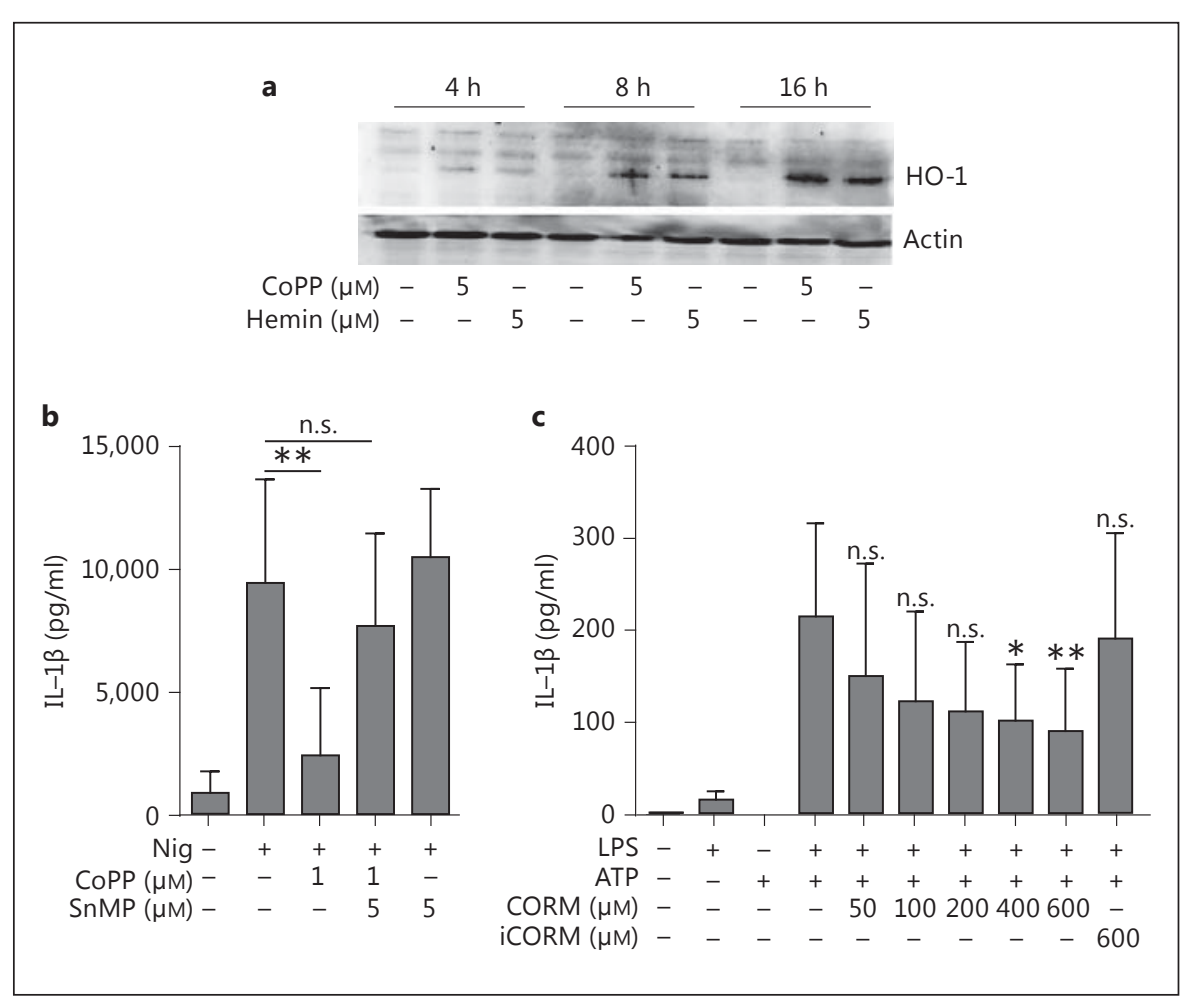

Hemin and CoPP Inhibit NLRP3

Activation by Enhancing Autophagy
J Innate Immun 2017;9:65-82 DOI: $10.1159 / 000448894$ 


\section{a}
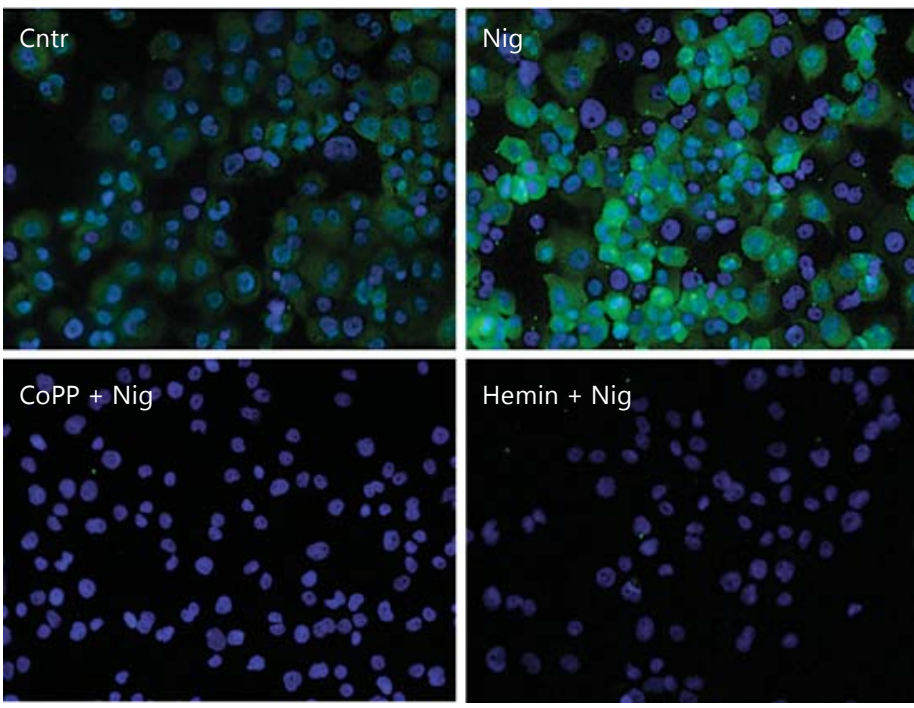

Hemin + Nig
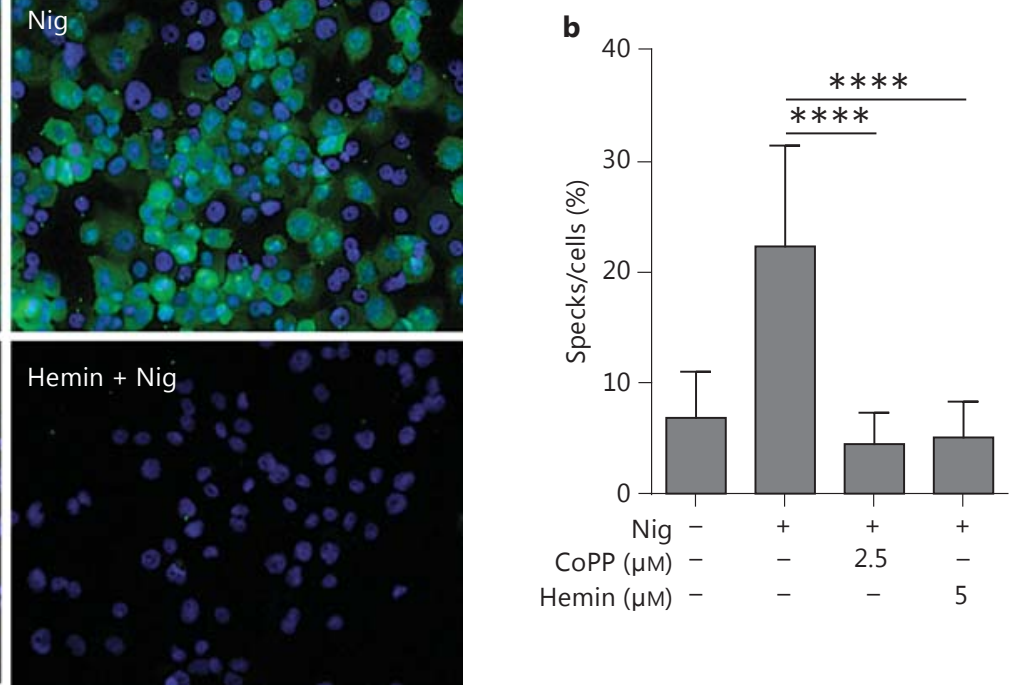

Hemin $(\mu \mathrm{M})-\quad \quad-\quad \quad-\quad 5$

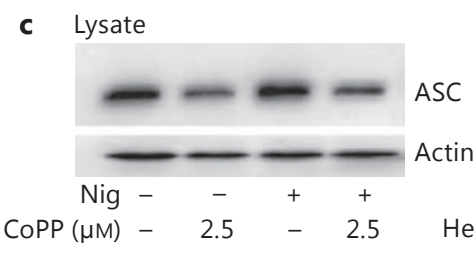

d

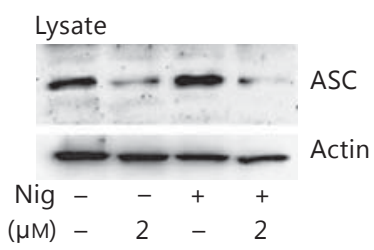

e

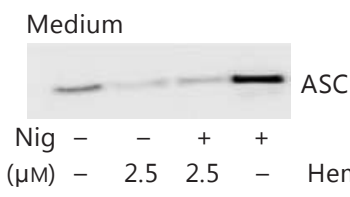

f Medium

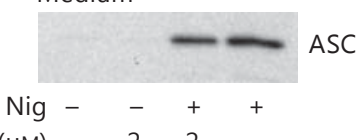

$\operatorname{CoPP}(\mu \mathrm{M})-2.52 .5-\operatorname{Hemin}(\mu \mathrm{M})-22$ -

Fig. 6. Hemin and CoPP block ASC speck formation. a, b THP-1 macrophages were incubated for $3 \mathrm{~h}$ in the presence of CoPP or hemin, and activated with nigericin (Nig.). Speck formation was visualized by staining for ASC (green) and DNA (blue, DAPI). a Representative of 4 individual experiments. $\mathbf{b}$ The extent of speck formation was determined by dividing the number of the specks by the number of nuclei per field. Statistical significance was eval-

ficient TEPMs, whether nonactivated or nigericin-activated (online suppl. fig. 2J). However, the reduction was not statistically significant. Elevated secretion of IL- $1 \beta$ was observed in the nigericin-activated TEPMs of HO1-deficient mice compared to TEPMs derived from the WT littermates (LysMCre ${ }^{-/-} \mathrm{HMOX1}^{\mathrm{fl} / \mathrm{fl}}$ ), supporting the hypothesis that HO-1 can function as an endogenous regulator of the NLRP3 inflammasome (online suppl. fig. $2 \mathrm{~K})$.

The inhibitory effect of CoPP and hemin on the secretion of IL- $1 \beta$ by the HO-1-deficient TEPMs was comparable with the inhibition observed in the TEPMs derived from the WT littermates (online suppl. fig. 2K). These results argue against the hypothesis proposing a role for CoPP- and hemin-induced HO-1 as a mechanism of uated with $\log _{2}$-transformed values. Data represent the means \pm SD of 4 individual experiments. ${ }^{* * *} \mathrm{p} \leq 0.0001$. c-f THP- 1 macrophages were incubated in the presence of $\operatorname{CoPP}(\mathbf{c}, \mathbf{e})$ or hemin $(\mathbf{d}, \mathbf{f})$ and activated with nigericin. Western blots of ASC (22 kDa) (c, d) of the cell lysates and medium (e, f). Western blots shown are representative of 4 (c-e) or 5 (f) individual experiments.

NLRP3 inflammasome inhibition. However, it should be noted that CoPP and hemin treatment was able to increase Hmoxl expression, also in the HO-1- deficient TEPMs (online suppl. fig. 2J). Altogether, the data above suggest that induction of HO-1 may contribute to the inhibitory effect of hemin and CoPP. Nevertheless, due to the limitations of the HO-1-deficient mouse model, i.e. the deletion of Hmox 1 in TEPMs was not complete, such a role for HO-1 could not be ascertained.

\section{Hemin and CoPP Inhibit Inflammasome Complex \\ Formation by Depleting Intracellular ASC}

To further elucidate the mechanism by which CoPP and hemin inhibit inflammasome function, we studied their effect on the assembly of the NLRP3 inflammasome. 
The adaptor protein ASC is an obligatory mediator of molecular interactions between the receptor protein and procaspase-1 of the NLRP3 inflammasome [3]. Upon inflammasome activation, ASC-dimers aggregate and form large structures called ASC specks or ASC foci, typically $1 \mathrm{speck} /$ cell [6]. Nigericin induced a robust formation of ASC specks in THP-1 macrophages (fig. 6a, b). The incubation of THP-1 macrophages in the presence of hemin or CoPP prior to the nigericin-induced activation of the NLRP3 inflammasome not only abolished the speck formation but also dramatically reduced the level of ASC staining in the cytoplasm (fig. 6a). The reduction of the amount of intracellular ASC was further confirmed by Western blots of the cell lysates, which demonstrated that incubation of THP-1 macrophages in the presence of CoPP or hemin reduced the amount of ASC both in nonactivated and nigericin-activated cells (fig. $6 \mathrm{c}$, d; online suppl. fig. 3A, B).

A relatively low mRNA expression of endogenous ASC (on average Ct 26.9) was detected in THP-1 macrophages, and it could not be significantly induced by nigericin. Moreover, the treatment of THP-1 macrophages with CoPP or hemin had no significant impact on the expression of ASC mRNA (online suppl. fig. 3C). A robust release of ASC protein in the cell culture medium was observed in nigericin-activated THP-1 macrophages (fig. 6e, f; online suppl. fig. 3D, E). However, the nigericin-induced release of ASC was significantly diminished in cells pretreated with CoPP or hemin. These data suggest that the reduction of ASC was not due to the diminished gene expression of ASC or the increased secretion of ASC. Rather, the data support the idea that hemin and CoPP disrupt the inflammasome speck formation by reducing the amount of intracellular ASC.

\section{Hemin and CoPP Inhibit NLRP3 Activation by}

Enhancing Autophagy

The induction of autophagy has been shown to result in the degradation of inflammasome components $[12,13]$. Therefore, we next studied whether the degradation of ASC could be mediated via the induction of autophagy by hemin or CoPP. Microtubule-associated protein 1 light chain 3 (LC3) is an integral membrane protein of autophagic vesicles, which is required for the formation of autophagosomes [29]. An increased ratio of LC3-II to LC3-I has been shown to correlate with increased formation of autophagosomes [29]. In unprimed and LPS-primed human primary macrophages and THP-1 macrophages, CoPP increased the ratio of LC3-II to LC3-I in cells challenged with NLRP3 inflammasome activators (fig. 7a, b).
The oligomerization of SQSTM1 precedes the autophagosome formation [30]. In THP-1 macrophages, CoPP alone induced a robust formation of SQSTM1 oligomers compared to the diffuse SQSTM1 staining in nontreated cells (fig. 7c). In addition, in the presence of CoPP, ASC rather localized with nuclear DAPI-staining whereas ASC staining in nontreated cells appeared mostly cytoplasmic. SQSTM1 is degraded in the autophagosomes, and therefore the amount of intracellular SQSTM1 reflects the level of autophagosomal degradation, i.e. autophagic flux [31]. To determine the efficiency of autophagic flux, the degradation of SQSTM1 was studied in human primary macrophages. In the presence of LPS, the intracellular levels of SQSTM1 were increased compared to nonactivated cells (fig. 7d). In contrast, incubation of the human primary macrophages or THP-1 macrophages in the presence of CoPP, and to a lesser extent hemin, increased the degradation of SQSTM1 both in nonactivated and activated cells (fig. 7d, e; online suppl. fig. 4A, B). To further study whether CoPP- or hemin-induced depletion of ASC depended on autophagy, autophagic sequestration was inhibited with 3-methyl adenine (3-MA), a phosphoinositide 3-kinase inhibitor. As expected, the treatment of the THP-1 macrophages with 3-MA for 23 $\mathrm{h}$ diminished the ratio of LC3-II to LC3-I (online suppl. fig. 4C). Importantly, the treatment with 3-MA reversed the CoPP-induced depletion of intracellular ASC in both nonactivated and nigericin-activated THP-1 macrophages (fig. 7f; online suppl. fig. 4D). In conclusion, the data above suggest that hemin and CoPP enhance the degradation of ASC by increasing the autophagic flux, which results in reduced intracellular ASC levels and reduced activation of the NLRP3 inflammasome.

\section{Discussion}

The activation of the NLRP3 inflammasome and the consequent secretion of IL- $1 \beta$ and IL- 18 result in a robust inflammatory reaction, and thus stringent regulatory mechanisms of NLRP3 activation are required. In this study, we demonstrate that hemin may act as an important negative regulator of the NLRP3 inflammasome in macrophages. Pronounced inhibition of secretion of IL$1 \beta$ and IL-18 was observed in the presence of hemin or its derivative CoPP. Importantly, such an inhibitory effect could also be observed in vivo. Thus, the injection of CoPP into the peritoneal cavity prior to the activation of the NLRP3 inflammasome by MSU crystals attenuated peritonitis in mice by inhibiting the secretion of IL- $1 \beta$, as 
a

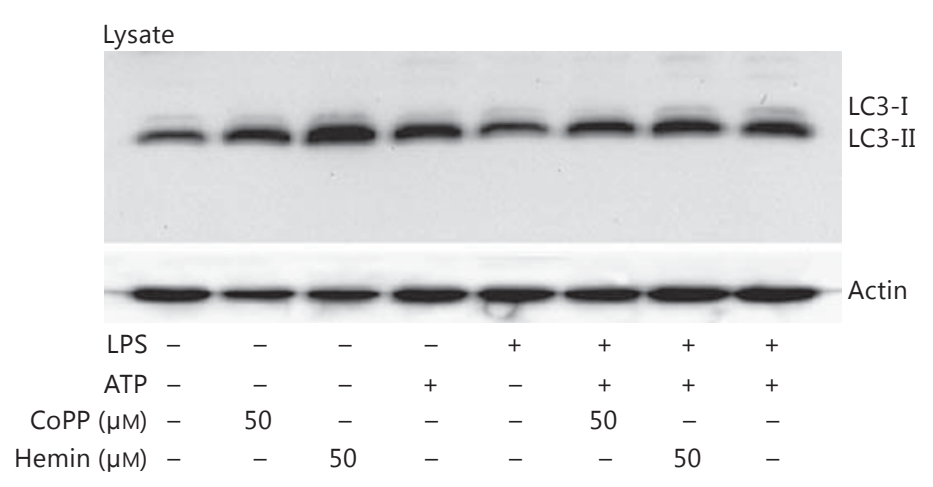

b
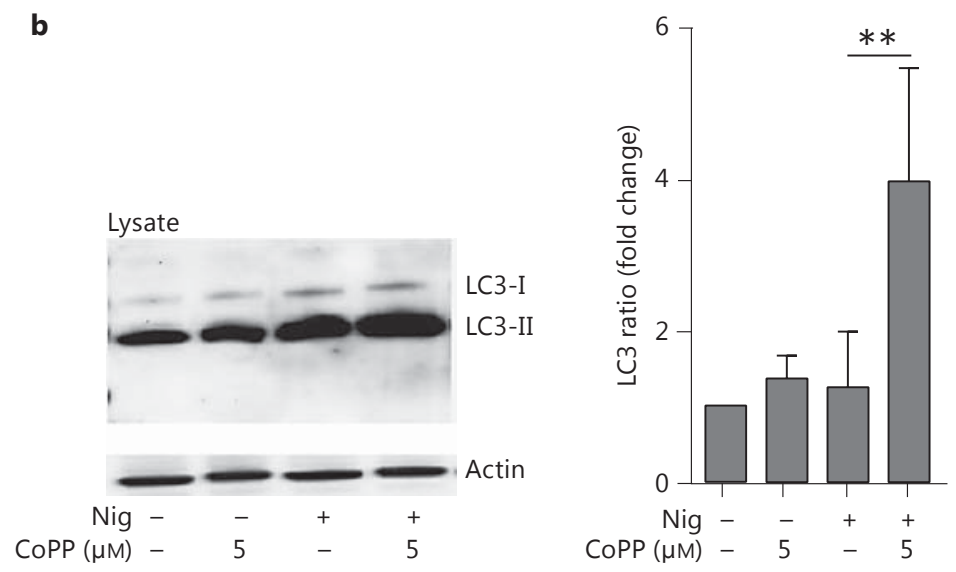
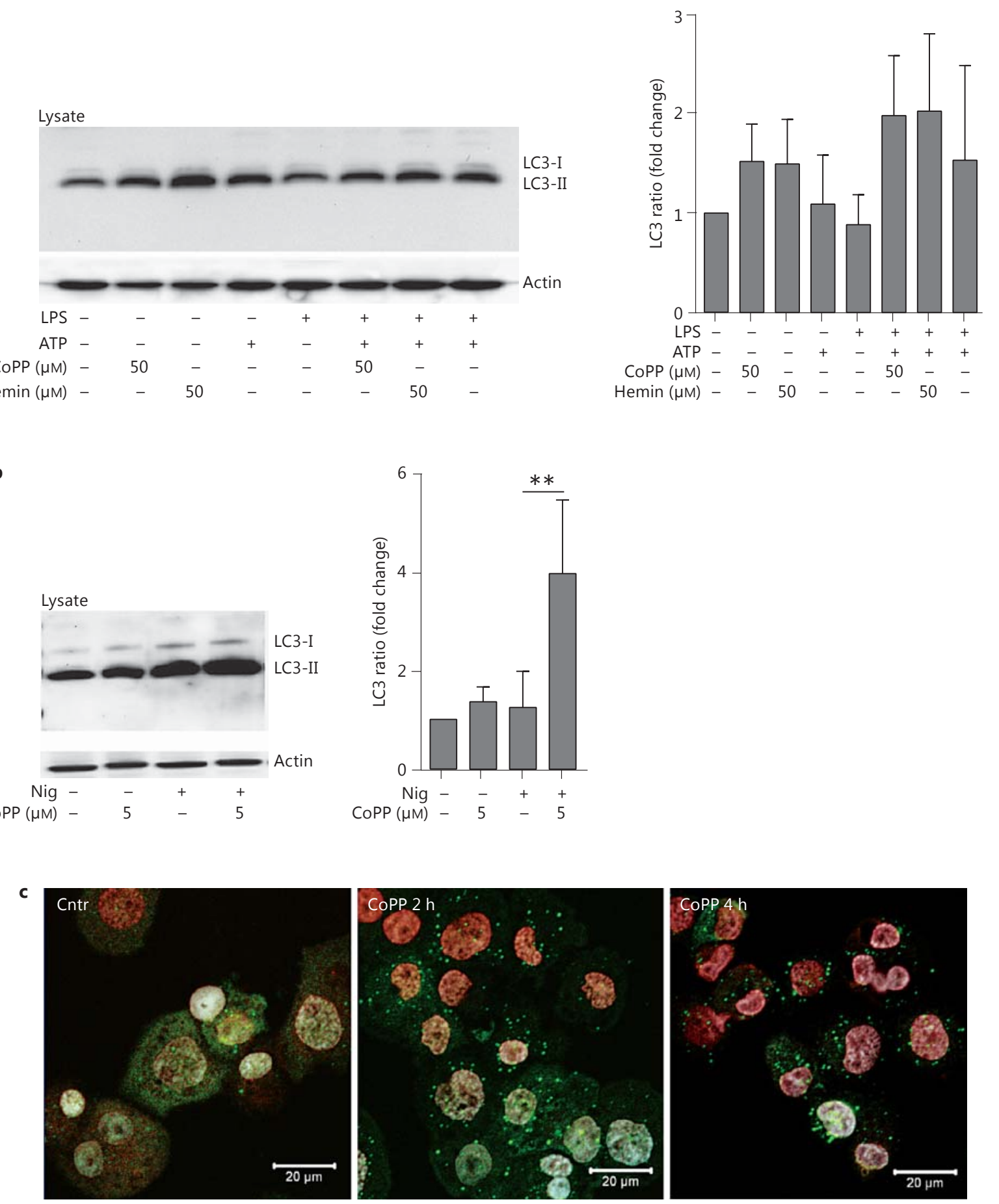

7

(For legend see next page.) 


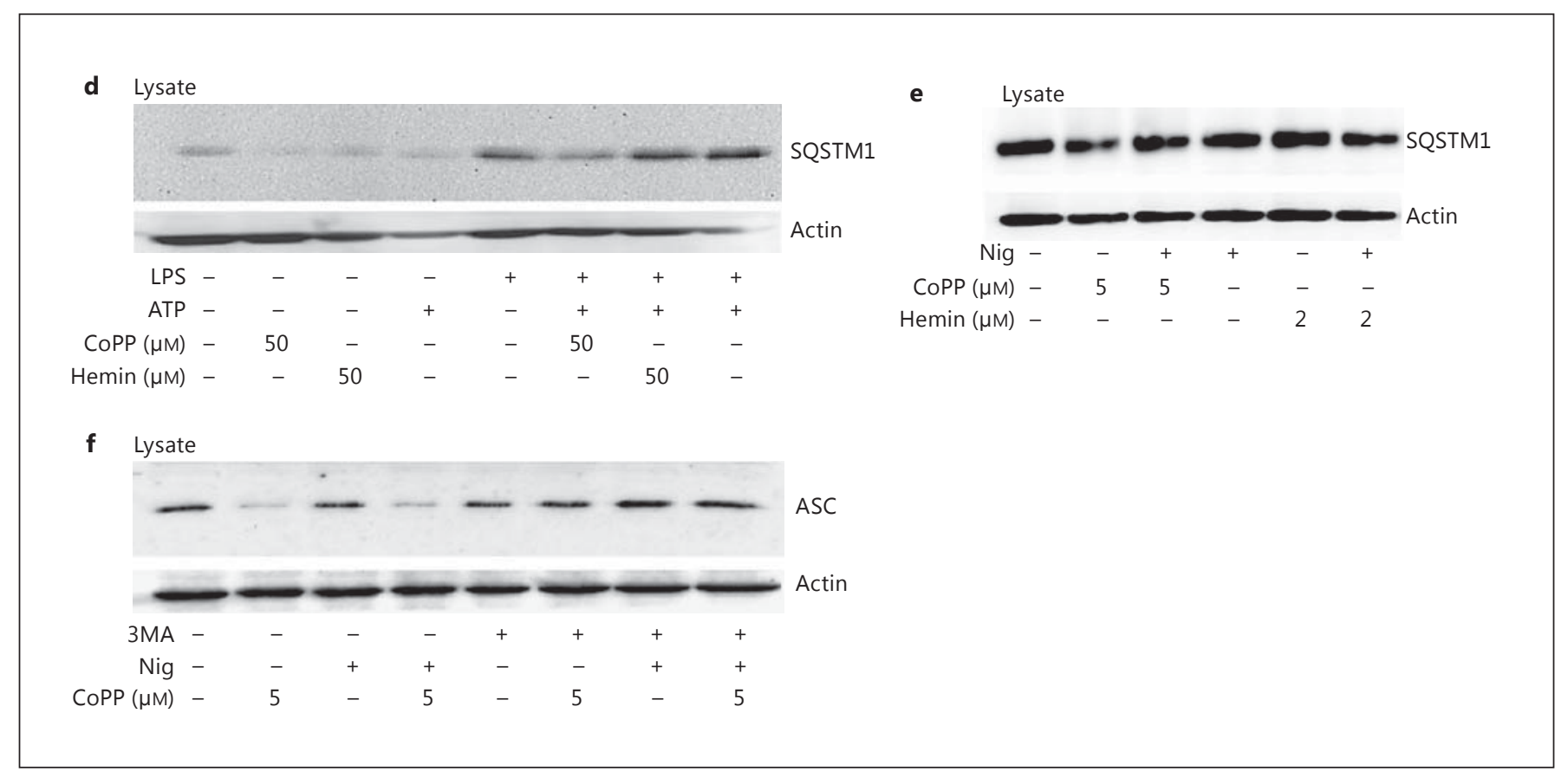

Fig. 7. Induction of autophagy contributes to the degradation of ASC. a, d Unprimed or LPS-primed human primary macrophages were incubated for $3 \mathrm{~h}$ in the presence of CoPP or hemin, and then activated with ATP. b, e THP-1 macrophages were incubated for $3 \mathrm{~h}$ in the presence of CoPP or hemin, and thereafter activated with nigericin (Nig.). a Western blot analysis and quantitation of LC3 (LC3-I $19 \mathrm{kDa}$ and LC3-II $17 \mathrm{kDa}$ ) bands of human primary macrophage lysates. $\mathbf{b}$ Western blot analysis and quantitation of LC3 (LC3-I $19 \mathrm{kDa}$ and LC3-II $17 \mathrm{kDa}$ ) bands of THP-1 macrophage lysates. ${ }^{* *} \mathrm{p} \leq 0.01$. a, $\mathbf{b}$ In the quantitations, the ratio of the intensities of the bands of LC3-I and LC3-II (LC3-II/LC3-I) are expressed as fold changes compared to the LC3 ratio determined from the nontreated cells. Data represent the means \pm SD. c THP-

well as by modestly reducing leukocyte recruitment into the peritoneal cavity (fig. 2e, f).

In the heme molecule, the iron atom can reversibly change its oxidative state [32]; in the ferrous $\left(\mathrm{Fe}^{2+}\right)$ state, the molecule is called 'heme', and in the ferric $\left(\mathrm{Fe}^{3+}\right)$ state, 'hemin' [32]. Previous studies have shown that, in the absence of other inflammasome activators, heme induces activation of the NLRP3 inflammasome [27, 33]. According to the results obtained by Dutra et al. [27], heme-induced processing of pro-IL-1 $\beta$ in vitro requires the presence of serum. Somewhat in contrast with these results, hemin was shown to ameliorate NLRP3 inflammasome activation during LPS- and D-galactosamine-induced liver injury [34] and sepsis-induced lung injury [35] in vivo as well as LPS-induced NLRP3 inflammasome activation in gingival cells in vitro [36], by reducing the TLR-induced expression of NLRP3 inflammasome components and the
1 macrophages were incubated in the presence of CoPP for the indicated times, and stained for SQSTM1 (green), ASC (red) and DNA (blue, DAPI; colors refer to the online version). $\mathbf{d}$ Western blot analysis of SQSTM1 (62 kDa) of human primary macrophage lysates. e Western blot analysis of SQSTM1 (62 kDa) of THP-1 macrophage lysates. $\mathbf{f}$ THP-1 macrophages were first incubated in the presence of autophagy inhibitor 3-MA, then for $3 \mathrm{~h}$ in the presence of CoPP, and finally activated with nigericin. Intracellular ASC (22 kDa) was assessed from the cell lysates by Western blot analysis. The Western blots or immunofluorescence microscopy images shown are representative of $3(\mathbf{b}), 4(\mathbf{a}, \mathbf{c}, \mathbf{f})$ or $5(\mathbf{d}, \mathbf{e})$ individual experiments.

ROS-dependent inflammasome complex formation. It remains to be elucidated why, under certain conditions, heme/hemin functions as an activator of the NLRP3 inflammasome, but, in the presence of NLRP3 inflammasome activators, exerts inhibitory action. Different experimental settings and the oxidation state of the iron may contribute to the variable effects of heme/hemin.

Activation of the NLRP3 inflammasome requires 2 separate signals: a priming signal, induced by the activation of the TLRs, during which the transcription of proIL- $1 \beta$ and NLRP 3 are induced and a second signal that is followed by the assembly and activation of the inflammasome complex [2]. In this study, macrophages were primed with LPS prior to treatment with hemin or CoPP and under these conditions, neither hemin nor CoPP had any significant inhibitory effect on the expression of $I L 1 B$ or NLRP3 (fig. $3 \mathrm{a}, \mathrm{b}$ ) or the protein levels of pro-IL-1 $\beta$, 
NLRP3 and procaspase-1 (fig. 3c, d). This suggests that hemin and CoPP did not reduce the priming of the inflammasome, but instead interfered with the formation or function of the inflammasome complex. In accordance with this, hemin and CoPP significantly reduced the formation of inflammasome complexes as reflected by the reduced formation of ASC specks (fig. 6a, b). NLRP3 receptor lacks the CARD domain and therefore the adaptor protein ASC is vital for the assembly and recruitment of procaspase- 1 to the inflammasome complex $[2,6]$. The reduction of inflammasome complex formation was most likely due to the reduced availability of intracellular ASC (fig. 6a, c, d). As the expression of ASC was not reduced, and the secretion of ASC protein was not enhanced in the presence of CoPP and hemin (online suppl. fig. 3C; fig. 6e, $\mathrm{f}$ ), the reduction in intracellular ASC levels was most likely caused by its increased degradation.

Autophagy has been suggested to restrict the activation of NLRP3 and AIM2 inflammasomes by targeting inflammasome components for degradation in the autophagosomes [13]. Several observations suggest that the heminand CoPP-induced reduction of ASC level was caused by increased autolysosomal degradation of ASC. Both hemin and $\mathrm{CoPP}$ increased the autophagosome formation as reflected by increased ratio of LC3-II to LC3-I (fig. 7a, b), and also enhanced the degradation of autophagosomal proteins, as reflected by the reduced levels of SQSTM1 (fig. 7d, e), which is degraded in the autophagosomes. Furthermore, CoPP could no longer induce the depletion of ASC in the presence of the autophagy inhibitor 3-MA (fig. 7f). Reduced production of mitochondrial ROS could have contributed to the inhibitory effect of hemin and CoPP. Since hemin and CoPP specifically reduced the accumulation of mitochondrial ROS, it is conceivable that the inhibitory effect of hemin and CoPP was mediated via enhanced autophagy that reduced the number of ROS producing mitochondria rather than via any HO-1-mediated antioxidant effects. Altogether, these findings strongly suggest that the induction of autophagy played a key role in the inhibition of inflammasome by hemin and CoPP.

Hemin has been shown to induce autophagic clearance of mitochondria in bovine endothelial cells and in a leukemic erythroblast cell line $[37,38]$; however, the exact mechanism by which hemin and CoPP activate the autophagy in macrophages remains to be elucidated. Several lines of evidence suggest that induction of HO-1 enzyme could contribute to the activation of autophagy. Carchman et al. [39] have demonstrated that HO-1 is necessary for the induction of autophagy in mouse hepatocytes. Furthermore, the HO-1-mediated degradation of heme to carbon monoxide has been shown to increase the intracellular level of LC3 protein, along with enhanced formation of autophagosomes [40]. In this study, an enzymatic inhibitor of HO-1, stannous mesoporphyrin, attenuated the CoPP-induced inhibition of IL- $1 \beta$ secretion (fig. 5b), suggesting the involvement of $\mathrm{HO}-1$. In addition, nigericin-induced secretion of IL- $1 \beta$ was enhanced in the HO-1-deficient macrophages (online suppl. fig. $2 \mathrm{~K}$ ). However, hemin and CoPP inhibited the inflammasome activation, also in the peritoneal macrophages of HO-1-deficient mice, which argues against the role of HO-1. It should be noted that the deletion of Hmox 1 in the peritoneal macrophages of $\mathrm{HO}$-1-deficient mice was incomplete, and thus it cannot be ruled out that the residual expression of Hmoxl in the LysMCre $^{+/-}$ HMOX $1^{\mathrm{fl} / \mathrm{fl}}$ mouse macrophages was sufficient to mediate the inhibitory effect of hemin and CoPP. In conclusion, it seems that the induction of HO- 1 may contribute to the inhibitory effect of hemin and CoPP on the secretion of IL- $1 \beta$ and activation of autophagy.

The role of heme/hemin in the regulation of NLRP3 inflammasome activation is intriguing. Despite its prooxidant and proinflammatory properties, in the presence of NLRP3 inflammasome activation hemin acts as an inhibitor. In numerous pathological conditions, such as severe inflammation and infections, tissue damage enhances the release of heme/hemin to the circulation. Reciprocally, to maintain homeostasis, the cytokines released during inflammation enhance the sequestration of heme/hemin to macrophages [1]. To avoid the excessive NLRP3 inflammasome activation caused by inflammasome activators generated during inflammation, it is crucial to possess efficient inhibitory mechanisms to restrict overwhelming inflammatory reactions. It is possible that hemin-induced autophagy has evolved to protect the cell from heme- and iron-induced oxidative damage to mitochondria [38]. However, CoPP and hemin inhibited the production of mitochondrial ROS triggered during the activation of the NLRP3 inflammasome, which may reflect hemin- or CoPP-induced enhancement of mitochondrial clearance via autophagy. Accordingly, hemin and CoPP may trigger autophagy as an inhibitory feedback mechanism to restrict the activation of the NLRP3 inflammasome by reducing the levels of inflammasome components and mitochondrial ROS $[13,14]$.

In cryopyrin-associated autoinflammatory diseases, dysregulated activation of NLRP3 is directly involved in the pathogenesis of the syndromes. Excessive activation of the NLRP3 inflammasome has also been implicated in other autoinflammatory diseases and, more recently, also 
in the pathogenesis of gout [8] and atherosclerosis $[4,5]$. Thus, the results of this study could provide a novel approach, for the treatment of not only difficult and lifethreatening autoinflammatory diseases but also more common chronic diseases, in which the activation of the NLRP3 inflammasome is involved.

\section{Acknowledgements}

The authors gratefully acknowledge Maija Atuegwu, Mari Jokinen, Päivi Alander and Santtu Hirvikorpi for excellent technical assistance, Anna-Kaisa Ruotsalainen (MSc) for expert assistance in animal breeding and Andrea Dichlberger for expertise in the quantitative real-time RT-PCR and primer design. Biomedicum FACS core facilities are acknowledged for providing flow cytometric services. This work was supported by the Wihuri Research Institute, maintained by the Jenny and Antti Wihuri Foundation, and also by grants from the Ida Montin Foundation, the Maire Lisko Foundation, the Aarne Koskelo Foundation, the Finnish Foundation for Cardiovascular Research, the Paulo Foundation, the Veritas Foundation and the Meilahti Foundation (to K.N.), the Sigrid Juselius Foundation and the Academy of Finland (to A.L.L.), the Stockmann Foundation, the Arthritis Society of Canada, the Canadian Institutes of Health Research (THC 135230) and Helsinki University Central Hospital research funds (to K.K.E.). The funders had no role in study design, data collection and analysis, decision to publish or preparation of the manuscript.

\section{References}

1 Ganz T, Nemeth E: Iron homeostasis in host defence and inflammation. Nat Rev Immunol 2015; 15:500-510

2 Latz E, Xiao TS, Stutz A: Activation and regulation of the inflammasomes. Nat Rev Immunol 2013;13:397-411.

3 Davis BK, Wen H, Ting JP: The inflammasome NLRs in immunity, inflammation, and associated diseases. Annu Rev Immunol 2011; 29:707-735

4 Duewell P, Kono H, Rayner KJ, Sirois CM, Vladimer G, Bauernfeind FG, Abela GS, Franchi L, Nunez G, Schnurr M, Espevik T, Lien E, Fitzgerald KA, Rock KL, Moore KJ, Wright SD, Hornung V, Latz E: NLRP3 inflammasomes are required for atherogenesis and activated by cholesterol crystals. Nature 2010;464:1357-1361.

5 Rajamäki K, Lappalainen J, Öörni K, Välimäki E, Matikainen S, Kovanen PT, Eklund KK: Cholesterol crystals activate the NLRP3 inflammasome in human macrophages: a novel link between cholesterol metabolism and inflammation. PLoS One 2010;5:e11765.

6 Lu A, Magupalli VG, Ruan J, Yin Q, Atianand MK, Vos MR, Schroder GF, Fitzgerald KA, Wu $\mathrm{H}$, Egelman EH: Unified polymerization mechanism for the assembly of ASC-dependent inflammasomes. Cell 2014;156:1193-1206.

7 Bauernfeind FG, Horvath G, Stutz A, Alnemri ES, MacDonald K, Speert D, FernandesAlnemri T, Wu J, Monks BG, Fitzgerald KA, Hornung V, Latz E: Cutting edge: NF-kappaB activating pattern recognition and cytokine receptors license NLRP3 inflammasome activation by regulating NLRP3 expression. J Immunol 2009;183:787-791.

8 Martinon F, Petrilli V, Mayor A, Tardivel A, Tschopp J: Gout-associated uric acid crystals activate the NALP3 inflammasome. Nature 2006;440:237-241.

9 Stehlik C, Dorfleutner A: COPs and POPs: modulators of inflammasome activity. J Immunol 2007;179:7993-7998.
10 Pedraza-Alva G, Perez-Martinez L, ValdezHernandez L, Meza-Sosa KF, Ando-Kuri M: Negative regulation of the inflammasome: keeping inflammation under control. Immunol Rev 2015;265:231-257.

11 Mizushima N, Yoshimori T, Ohsumi Y: The role of ATG proteins in autophagosome formation. Annu Rev Cell Dev Biol 2011;27:107132.

12 Harris J, Hartman M, Roche C, Zeng SG, O'Shea A, Sharp FA, Lambe EM, Creagh EM, Golenbock DT, Tschopp J, Kornfeld H, Fitzgerald KA, Lavelle EC: Autophagy controls IL-1beta secretion by targeting pro-IL1beta for degradation. J Biol Chem 2011;286: 9587-9597.

13 Shi CS, Shenderov K, Huang NN, Kabat J, Abu-Asab M, Fitzgerald KA, Sher A, Kehrl $\mathrm{JH}$ : Activation of autophagy by inflammatory signals limits IL-1beta production by targeting ubiquitinated inflammasomes for destruction. Nat Immunol 2012;13:255-263.

14 Zhou R, Yazdi AS, Menu P, Tschopp J: A role for mitochondria in NLRP3 inflammasome activation. Nature 2011;469:221-225.

15 Dupont N, Jiang S, Pilli M, Ornatowski W, Bhattacharya D, Deretic V: Autophagy-based unconventional secretory pathway for extracellular delivery of IL-1beta. EMBO J 2011;30: 4701-4711.

16 Clark JE, Naughton P, Shurey S, Green CJ, Johnson TR, Mann BE, Foresti R, Motterlini R: Cardioprotective actions by a water-soluble carbon monoxide-releasing molecule. Circ Res 2003;93:e2-e8.

17 Scanu A, Oliviero F, Gruaz L, Sfriso P, Pozzuoli A, Frezzato F, Agostini C, Burger D, Punzi L: High-density lipoproteins downregulate CCL2 production in human fibroblastlike synoviocytes stimulated by urate crystals. Arthritis Res Ther 2010;12:R23.
18 Tzima S, Victoratos P, Kranidioti K, Alexiou M, Kollias G: Myeloid heme oxygenase-1 regulates innate immunity and autoimmunity by modulating IFN-beta production. J Exp Med 2009;206:1167-1179.

19 Clausen BE, Burkhardt C, Reith W, Renkawitz R, Forster I: Conditional gene targeting in macrophages and granulocytes using LysMcre mice. Transgenic Res 1999;8:265277

20 Nakanishi S, Vikstedt R, Söderlund S, LeeRueckert M, Hiukka A, Ehnholm C, Muilu M, Metso J, Naukkarinen J, Palotie L, Kovanen PT, Jauhiainen M, Taskinen MR: Serum, but not monocyte macrophage foam cells derived from low HDL-C subjects, displays reduced cholesterol efflux capacity. J Lipid Res 2009; 50:183-192.

21 Niemi K, Teirilä L, Lappalainen J, Rajamäki K, Baumann MH, Öörni K, Wolff H, Kovanen PT, Matikainen S, Eklund KK: Serum amyloid $A$ activates the NLRP3 inflammasome via $\mathrm{P} 2 \mathrm{X} 7$ receptor and a cathepsin B-sensitive pathway. J Immunol 2011;186:6119-6128.

22 Nurmi K, Virkanen J, Rajamäki K, Niemi K, Kovanen PT, Eklund KK: Ethanol inhibits activation of NLRP3 and AIM2 inflammasomes in human macrophages - a novel anti-inflammatory action of alcohol. PLoS One 2013; 8:e78537.

23 Athale J, Ulrich A, MacGarvey NC, Bartz RR, Welty-Wolf KE, Suliman HB, Piantadosi CA: Nrf2 promotes alveolar mitochondrial biogenesis and resolution of lung injury in Staphylococcus aureus pneumonia in mice. Free Radic Biol Med 2012;53:1584-1594.

24 Hentze H, Lin XY, Choi MS, Porter AG: Critical role for cathepsin B in mediating caspase1-dependent interleukin-18 maturation and caspase-1-independent necrosis triggered by the microbial toxin nigericin. Cell Death Differ 2003; 10:956-968.
Hemin and CoPP Inhibit NLRP3

Activation by Enhancing Autophagy
J Innate Immun 2017;9:65-82 DOI: $10.1159 / 000448894$ 
25 International Organization for Standardization 17294-2: 2005 water quality. Application of inductively coupled plasma mass spectrometry (ICP-MS). 2. Determination of 62 elements. Geneva, ISO, 2005.

26 Lin XY, Choi MS, Porter AG: Expression analysis of the human caspase-1 subfamily reveals specific regulation of the CASP 5 gene by lipopolysaccharide and interferon-gamma. J Biol Chem 2000;275:39920-39926.

27 Dutra FF, Alves LS, Rodrigues D, Fernandez PL, de Oliveira RB, Golenbock DT, Zamboni DS, Bozza MT: Hemolysis-induced lethality involves inflammasome activation by heme. Proc Natl Acad Sci USA 2014;111:E4110E4118.

28 Abraham NG, Kappas A: Pharmacological and clinical aspects of heme oxygenase. Pharmacol Rev 2008;60:79-127.

29 Mizushima N: Methods for monitoring autophagy. Int J Biochem Cell Biol 2004;36: 2491-2502.

30 Itakura E, Mizushima N: p62 targeting to the autophagosome formation site requires selfoligomerization but not LC3 binding. J Cell Biol 2011;192:17-27.
31 Larsen KB, Lamark T, Overvatn A, Harneshaug I, Johansen T, Bjorkoy G: A reporter cell system to monitor autophagy based on p62/SQSTM1. Autophagy 2010;6:784-793.

32 Larsen R, Gouveia Z, Soares MP, Gozzelino R: Heme cytotoxicity and the pathogenesis of immune-mediated inflammatory diseases. Front Pharmacol 2012;3:77.

33 Li Q, Fu W, Yao J, Ji Z, Wang Y, Zhou Z, Yan $\mathrm{J}$, Li W: Heme induces IL-1beta secretion through activating NLRP3 in kidney inflammation. Cell Biochem Biophys 2014;69:495502.

34 Kim SJ, Lee SM: NLRP3 inflammasome activation in $\mathrm{D}$-galactosamine and lipopolysaccharide-induced acute liver failure: role of heme oxygenase-1. Free Radic Biol Med 2013; 65:997-1004.

35 Luo YP, Jiang L, Kang K, Fei DS, Meng XL, Nan CC, Pan SH, Zhao MR, Zhao MY: Hemin inhibits NLRP3 inflammasome activation in sepsis-induced acute lung injury, involving heme oxygenase-1. Int Immunopharmacol 2014;20:24-32.
36 Li H, Zhou X, Zhang J: Induction of heme oxygenase-1 attenuates lipopolysaccharide-induced inflammasome activation in human gingival epithelial cells. Int J Mol Med 2014; 34:1039-1044.

37 Higdon AN, Benavides GA, Chacko BK, Ouyang X, Johnson MS, Landar A, Zhang J, Darley-Usmar VM: Hemin causes mitochondrial dysfunction in endothelial cells through promoting lipid peroxidation: the protective role of autophagy. Am J Physiol Heart Circ Physiol 2012;302:H1394-H1409.

38 Fader CM, Salassa BN, Grosso RA, Vergara AN, Colombo MI: Hemin induces mitophagy in a leukemic erythroblast cell line. Biol Cell 2016;108:77-95.

39 Carchman EH, Rao J, Loughran PA, Rosengart MR, Zuckerbraun BS: Heme oxygenase1-mediated autophagy protects against hepatocyte cell death and hepatic injury from infection/sepsis in mice. Hepatology 2011;53: 2053-2062.

40 Lee SJ, Ryter SW, Xu JF, Nakahira K, Kim HP Choi AM, Kim YS: Carbon monoxide activates autophagy via mitochondrial reactive oxygen species formation. Am J Respir Cell Mol Biol 2011;45:867-873. 